\title{
Estrutura arbórea da Floresta Ombrófila Densa Altomontana de serras do Sul do Brasil ${ }^{1}$
}

\author{
Maurício Bergamini Scheer ${ }^{2,3,5}$, Alan Yukio Mocochinski ${ }^{4}$ e Carlos Vellozo Roderjan ${ }^{2}$
}

Recebido em 21/09/2010. Aceito em 16/06/2011

\begin{abstract}
RESUMO
(Estrutura arbórea da Floresta Ombrófila Densa Altomontana de serras do Sul do Brasil). O presente trabalho teve os objetivos de agrupar informações sobre a estrutura arbórea da floresta altomontana da Serra do Mar paranaense e de compará-las com as de florestas altomontanas de outras serras do Sul e Sudeste do Brasil. Foram realizados levantamentos fitossociológicos em diversas montanhas de quatro importantes serras (ou subserras) do Paraná. Nas quatro subserras foram amostrados 2294 indivíduos ( $\mathrm{PAP} \geq 10 \mathrm{~cm}$ ) pertencentes a 28 famílias, 43 gêneros e 78 espécies. Foi observada maior riqueza de espécies na amostragem da Serra Gigante (41 espécies), seguida pelas serras da Prata (37), da Igreja (34) e do Ibitiraquire (26). A altura média obtida para os indivíduos foi de 4,8 m, o PAP médio de $22,9 \mathrm{~cm}$, a densidade média de $4779 \mathrm{ind} / \mathrm{ha}$, a área basal média de $33,5 \mathrm{~m}^{2} /$ ha e o índice de diversidade de Shannon total de 2,68 nat/ind. Agrupando informações de estudos realizados em outras subserras paranaenses, totalizando 11 levantamentos e 204 parcelas $\left(10200 \mathrm{~m}^{2}\right)$, obteve-se uma matriz com 75 espécies determinadas, onde as cinco com maior porcentagem de importância estrutural foram Ilex microdonta, Siphoneugena reitzii, Drimys angustifolia, Ocotea porosa e Ilex chamaedrifolia. Os trechos amostrados na Serra do Mar do Paraná, apresentaram menor riqueza e diversidade que os da Serra da Mantiqueira (MG) e maior que os dos Aparados da Serra Geral (SC). Tais diferenças, possivelmente, estão relacionadas às influências antrópicas, das distâncias geográficas, dos diferentes centros de endemismo, dos entornos tropicais ou subtropicais dominantes, das feições geomorfológicas, entre outros fatores.
\end{abstract}

Palavras-chave: Fitossociologia; Floresta altimontana; Floresta Atlântica; Floresta nebular tropical/subtropical; Serra do Mar

\begin{abstract}
(Tree component structure of tropical upper montane rain forests in Southern Brazil). The aims of this study were: (1) to group information about the tree structure of the upper montane rain forest of Serra do Mar in the state of Paraná (PR), Southern Brazil; and (2) to compare this information with available data from other mountain ranges in Southern and Southeastern Brazil. In the four mountain ranges studied, 2294 tree individuals (perimeter at breast height - $\mathrm{PBH} \geq 10 \mathrm{~cm}$ ) were sampled, which included 28 families, 43 genera and 78 species. The cloud forest sampled in Serra Gigante showed the highest richness (41 species), followed by Serra da Prata (37), Serra da Igreja (34) and Serra do Ibitiraquire (26). The mean tree height was $4.8 \mathrm{~m}$, the PBH was $22.9 \mathrm{~cm}$, the tree abundance was $4779 \mathrm{in} /$ ha, the basal area was $33.5 \mathrm{~m}^{2} /$ ha and the Shannon diversity index was 2.68 nats/ind. Combining our data with the published data on the Serra do Mar region, resulting in a total of 11 surveys and 204 plots $\left(10200 \mathrm{~m}^{2}\right)$, a matrix with 75 identified species was obtained. In this matrix, the five most important species in the structure of the forest were Ilex microdonta, Siphoneugena reitzii, Drimys angustifolia, Ocotea porosa and Ilex chamaedrifolia. The cloud forests sampled in Serra do Mar showed lower richness and diversity indexes than the cloud forests in Serra da Mantiqueira (Southeast) and higher richness and diversity than cloud forests in Aparados da Serra Geral (South). These differences are possibly related to the anthropic influences, geographic distances, different centers of endemism, the tropical and subtropical surroundings, and geomorphology, among other factors.
\end{abstract}

Key words: Atlantic Rain Forest; Phytosociology; Sea Mountain Range; Tropical/Subtropical Upper Montane Cloud/ Dwarf Forest

1 Parte da tese de Doutorado do primeiro Autor

2 Universidade Federal do Paraná, Programa de Pós-Graduação em Engenharia Florestal, Curitiba, PR, Brasil

3 Companhia de Saneamento do Paraná, Assessoria de Pesquisa e Desenvolvimento, Diretoria do Meio Ambiente e Ação Social, Curitiba, PR, Brasil

4 Coordenação de Aperfeiçoamento de Pessoal de Nível Superior, Brasilia, DF, Brasil

5 Autor para correspondência: mauriciobs@sanepar.com.br 


\section{Introdução}

As florestas que ocupam as porções mais elevadas das montanhas possuem composição florística e estrutura diferentes das florestas ocorrentes nos patamares mais baixos (Beard 1944/1955, Leigh 1975, Bruijnzeel 2000, Bruijnzeel \& Hamilton 2000). À medida que as florestas se aproximam dos topos de cumeeiras altomontanas, passam a se constituir de apenas um único estrato vertical, composto por árvores de porte reduzido, com ramos tortuosos, com folhas pequenas e coriáceas e densamente cobertos por epífitas, principalmente avasculares (Leigh 1975, Doumenge et al. 1995, Hamilton et al. 1995). Mesmo as árvores com maior comprimento de tronco são inclinadas no sentido ascendente das vertentes não superando o dossel compacto (Koehler et al. 2002). Além das feições geomórficas e dos solos, a ação dos ventos, a diminuição de temperaturas e a presença persistente ou frequente de nuvens contribuem para menores taxas de decomposição da serapilheira, de absorção de nutrientes e de produtividade primária (Leigh 1975).

Inúmeras funcionalidades e serviços ambientais/ecossistêmicos das florestas altomontanas têm sido frequentemente expostas na literatura já há algum tempo (Stadmuller 1987, Bruijnzeel \& Proctor 1995, Hamilton et al. 1995, Bruijnzeel 2000, Becker et al. 2006, Martínez et al. 2009, Scheer 2010). Entre essas funcionalidades estão aquelas relacionadas à proteção de encostas (Becker et al. 2006), ao aporte adicional de água pela interceptação das nuvens nas cabeceiras de bacias hidrográficas (Hamilton et al. 1995, Bruijnzeel \& Proctor 1995), ao estoque de significativas quantidades de carbono e água (Bolstad \& Vose 2005, Martínez et al. 2009, Scheer et al. 2011), à biodiversidade - por abrigar um grande número de espécies endêmicas e ameaçadas de extinção, muitas delas devido ao desmatamento de ecossistemas de menores altitudes (Hamilton et al. 1995, Becker et al. 2006, Bruijnzeel 2000)-, à capacidade de servir como referência para o monitoramento de mudanças climáticas no ecótono com ecossistemas adjacentes a montante (Becker et al. 2006), ao controle biológico, à polinização, à disponibilidade de recursos para a fauna, à recreação, entre outros (Martínez et al. 2009). Porém, estudos em florestas altomontanas ainda são escassos (Hamilton et al. 1995, Bruijnzeel \& Proctor 1995, Bruijnzeel 2000, Scheer 2010). Informações sobre quais seres vivos habitam os ambientes altomontanos, como eles ocupam o espaço e se regeneram, como eles interagem entre si e com o meio físico e qual é sua relevância na "prestação de serviços ambientais/ecossistêmicos" ainda não estão bem consolidadas de forma que possam repercurtir no meio científico dando suporte às autoridades governamentais e a sociedade para o desenvolvimento de ações significativas de proteção e de restauração de tais ambientes.

A grande extensão geográfica do Brasil, aliada à diversidade de condições climáticas, geológicas e geomorfológicas, permite que as florestas altomontanas ocorram em regiões fitogeográficas distintas, como as Florestas Estacionais Deciduais e Semideciduais, Ombrófilas Mistas e Densas. Dentro de cada região, as florestas altomontanas apresentam diferentes condições relacionadas à exposição das encostas, formas, comprimentos e declividades de rampas, profundidades e classes de solos, áreas transicionais, distâncias em relação ao oceano, gradientes altitudinais, extensão de serras, entre outras.

No Paraná, alguns trabalhos descreveram a estrutura arbórea (Roderjan 1994, Rocha 1999, Portes et al. 2001, Koehler et al. 2002) e a florística vascular (Scheer \& Mocochinski 2009) de trechos da Floresta Ombrófila Densa Altomontana (FODAM), todos localizados em áreas da Serra do Mar. Florestas Ombrófilas Altomontanas em Santa Catarina foram descritas por Falkenberg \& Voltolini (1995) e por Falkenberg (2003). Para Florestas Ombrófilas Altomontanas da região Sudeste do Brasil, foram publicados os trabalhos de França \& Stehmann (2004) e Meireles et al. (2008). Ainda nesta mesma região, abordando as florestas consideradas altomontanas, mas com características montanas, foi realizado o trabalho de Carvalho et al. (2005), e para formação de Floresta Estacional Semidecidual, o trabalho de Oliveira-Filho et al. (2004).

Dando continuidade aos estudos sobre ambientes altomontanos no Paraná, realizados por Mocochinski \& Scheer (2008) e por Scheer \& Mocochinski (2009), o presente trabalho teve o objetivo principal de agrupar as informações sobre a estrutura arbórea da Floresta Ombrófila Densa Altomontana da Serra do Mar paranaense e de compará-las com as de florestas altomontanas de outras serras do Sul e Sudeste do Brasil. Foram realizados levantamentos fitossociológicos em diversas montanhas de quatro importantes "subserras" no Paraná: Serra do Ibitiraquire, Serra da Igreja, Serra da Prata e Serra Gigante. Os dados obtidos em campo foram somados aos dados de mais sete levantamentos realizados em outras cinco subserras da Serra do Mar, disponíveis na literatura, e foram comparados com dados disponíveis para florestas altomontanas dos Aparados da Serra Geral (SC) e da Serra da Mantiqueira (MG). A partir das informações analisadas, foi possível indicar: (1) valores para os principais parâmetros da estrutura e diversidade arbórea da floresta altomontana da Serra do Mar paranaense; (2) quais espécies são mais abundantes, dominantes e frequentes; (3) se, com o aumento altitudinal dentro do patamar altomontano, há uma diminuição na diversidade e riqueza de espécies por unidade de área com participação significativa na estrutura da floresta; (4) quais espécies são comuns à maioria das áreas altomontanas, nas regiões Sul e Sudeste do Brasil; (5) quais florestas possuem maior similaridade em função dos valores de importância das espécies que as compõem e; (6) quais locais explicam a maior variabilidade nas densidades das espécies mais importantes do estudo. 


\section{Material e métodos}

\section{Áreas de estudo}

No Paraná, a Floresta Ombrófila Densa cobre a maior extensão das montanhas da Serra do Mar, atingindo, a formação altomontana, as porções mais elevadas das encostas, geralmente entre 1200 e 1800 m s.n.m.. Em alguns trechos, a oeste, ocorre o ecótono entre esta e a Floresta Ombrófila Mista Montana, a aproximadamente 1100 m s.n.m., com ocorrência de Araucaria angustifolia (Bertol.) Kuntze. Já nas porções mais elevadas das montanhas, passam a ocorrer os campos altomontanos.

O clima da região onde estão situadas as florestas altomontanas da Serra do Mar paranaense é classificado como Cfb, segundo Köppen, sendo subtropical, sempre úmido e com a temperatura média do mês mais frio abaixo de $18^{\circ} \mathrm{C}$ e superior a $-3{ }^{\circ} \mathrm{C}$ e a média do mês mais quente inferior a $22^{\circ} \mathrm{C}$ (Roderjan 1994). Roderjan \& Grodski (1999) observaram temperatura mínima absoluta de $-5^{\circ} \mathrm{C}$, média anual de $13,4^{\circ} \mathrm{C}$ e máxima absoluta de $30^{\circ} \mathrm{C}$ para patamares altomontanos a $1385 \mathrm{~m}$ s.n.m., em ambiente florestal do Morro do Anhangava, no município de Quatro Barras, Paraná. As precipitações pluvuimétricasas na Serra do Mar são bem distribuídas ao longo do ano e apresentam grande variação em função da topografia local. Medições na região litorânea ultrapassam $2000 \mathrm{~mm}$ anuais e nas encostas da serra os valores chegam a $3500 \mathrm{~mm}$ (Maack 2002).
O presente estudo foi realizado em quatro subserras pertencentes ao Complexo Serra do Mar no Paraná, localizadas nas coordenadas $26^{\circ} 00^{\prime} \mathrm{S}$ e $49^{\circ} 30^{\prime} \mathrm{W}$ e $25^{\circ} 00^{\prime} \mathrm{S}$ e $48^{\circ} 00^{\prime} \mathrm{W}$, denominadas regionalmente de: Serra do Ibitiraquire, Serra da Igreja, Serra da Prata e Serra Gigante (Fig. 1). A escolha destes locais levou em consideração a representatividade da área de ocorrência da Floresta Ombrófila Densa Altomontana no Paraná, a inclusão de diferenças marcantes em altitude (entre 950 e $1850 \mathrm{~m}$ ), em amplitude altitudinal, em extensão, em posição geográfica e em continentalidade dessa formação (ver detalhes em Scheer \& Mocochinski 2009). Os solos analisados em formações altomontanas paranaenses são extremamente ácidos, com altos teores de matéria orgânica, baixa saturação por bases e altos teores de alumínio trocável (Rocha 1999, Roderjan et al. 2002, Scheer et al. 2011). Nos trechos amostrados na Serra do Ibitiraquire (1500-1780 m s.n.m.), foram observados Neossolos Litólicos e Regolíticos. Nas Serras da Igreja (1310 m s.n.m.) e da Prata (1400 m s.n.m.) foram amostradas florestas sobre Gleissolos Háplicos, e na Serra Gigante (1000 m s.n.m.) Neossolos Litólicos e Cambissolos Húmicos.

\section{Levantamentos fitossociológicos e análises dos dados}

Para a amostragem da vegetação arbórea altomontana em cada subserra, foram instaladas aleatoriamente, ao longo de trilhas de acesso aos picos das montanhas, 24 parcelas
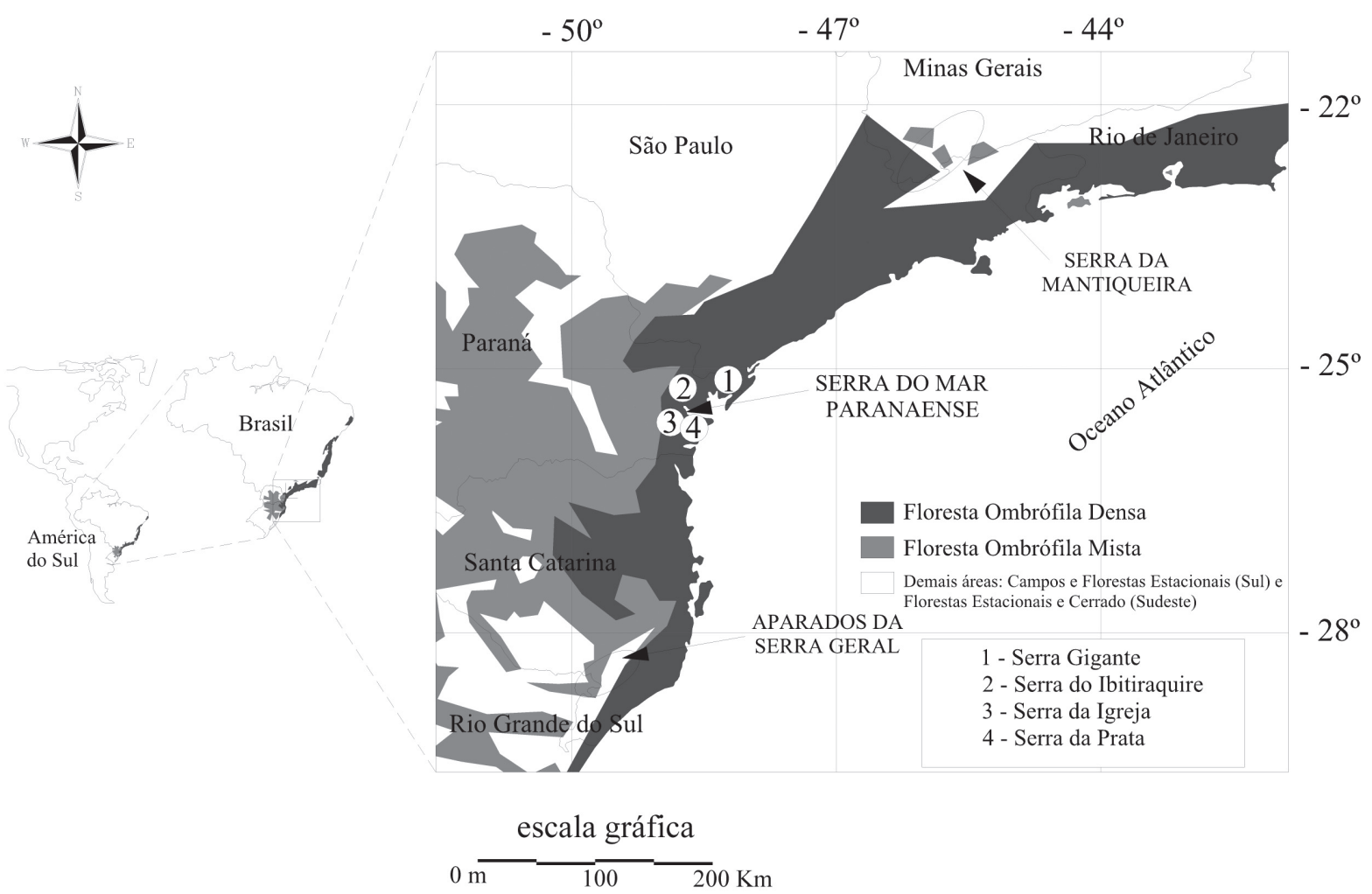

Figura 1. Localização das áreas de estudo no estado do Paraná. Adaptado de Scheer \& Mocochinski (2009). 
retangulares de $50 \mathrm{~m}^{2}(5 \times 10 \mathrm{~m})$, nas quais todos os indivíduos arbóreos com perímetro à altura do peito (PAP) $\geq 10$ $\mathrm{cm}$ foram identificados e mensurados. Foram registrados os valores de PAP e de altura total. A determinação das espécies foi realizada com o uso de chaves de identificação, comparação com material de herbários e confirmações com especialistas. Os procedimentos de identificação e os nomes completos das espécies, incluindo seus autores e famílias botânicas, podem ser encontrados em Scheer \& Mocochinski (2009) e na Fig. 6 deste trabalho. Utilizou-se a classificação taxonômica proposta por APG III (2009) para o reconhecimento das famílias de angiospermas. O material vegetal determinado foi depositado no Museu Botânico Municipal de Curitiba (MBM). Duplicatas foram doadas ao Herbário do Departamento de Botânica da Universidade Federal do Paraná (UPCB) e ao Herbário da Escola de Florestas de Curitiba (EFC).

Conforme a descrição de Scheer \& Mocochinski (2009), as amostragens foram efetuadas apenas em trechos de florestas com características primárias e bem conservadas, com aspectos estruturais e fisionômicos tipicamente altomontanos, como: presença de apenas um estrato arbóreo, com porte reduzido ( 3 a $7 \mathrm{~m}$ de altura), com troncos com muitas ramificações tortuosas e densamente cobertos por epífitas avasculares.

Os parâmetros estruturais densidade, frequência, dominância e porcentagem de importância das espécies arbóreas de cada trecho amostrado foram calculados de acordo com Mueller-Dombois \& Ellenberg (1974). Os diâmetros e alturas das árvores de cada uma das serras amostradas foram inseridos em classes. Foram calculados os índices de diversidade de Shannon ( $\left.\mathrm{H}^{\prime}\right)$ e de Equabilidade de Pielou (J'), conforme Magurran (1988). Os valores de H' foram comparados por testes de $t$ de Hutcheson (Zar 1996).

Análises de regressão linear foram realizadas utilizandose o programa Statigraphics Plus $4.1 \mathrm{com}$ o objetivo de verificar se o número de espécies por parcela diminui com o aumento de altitude, considerando as unidades amostrais (parcelas) das quatro subserras e considerando somente as parcelas da Serra do Ibitiraquire. Tal serra foi selecionada para essa análise devido ao fato da amostragem ter ocorrido no maior gradiente altitudinal entre as subserras avaliadas, de 1500 a 1780 m s.n.m.

Para elencar as espécies mais importantes da estrutura arbórea altomontana da Serra do Mar no Paraná, os dados do presente trabalho foram agrupados aos dados de mais sete levantamentos fitossociológicos realizados em cinco outras subserras paranaenses através dos estudos publicados por Roderjan (1994), Rocha (1999), Portes et al. (2001), Koehler et al. (2002), totalizando 11 levantamentos e 204 parcelas de $50 \mathrm{~m}^{2}$ (1,02 ha de área amostral e 4200 indivíduos medidos).

As análises de agrupamento foram feitas utilizando os dados das serras estudadas e de outras florestas brasileiras descritas como altomontanas localizadas nos Aparados da Serra Geral em Santa Catarina (Falkenberg 2003) e na Serra da Mantiqueira (França \& Stehmann 2004, Meireles et al. 2008) em Minas Gerais, relacionando-se os valores de importância relativos das espécies ocorrentes. Para estas análises, foram consideradas somente determinações em nível de espécie (165 espécies). O agrupamento foi realizado utilizando-se o programa Statigraphics Plus 4.1, através do método de Ward (variância mínima) e com a utilização da distância euclidiana quadrática como medida métrica.

Após a transformação dos dados $(\log (x+10))$, uma análise de componentes principais (ACP) foi realizada com a densidade de indivíduos das 30 espécies com maior porcentagem de importância nos 11 levantamentos das serras paranaenses. O programa utilizado foi o SSPS 11.0 para Windows. Foi utilizada uma matriz de correlação com a rotação varimax. Apenas os eixos com autovalores padronizados maiores que 1 foram selecionados. As variáveis (serras) com contribuição absoluta maior do que 0,6 (5\% de probabilidade de erro) foram consideradas importantes. Correlações de Spearman foram realizadas para investigar relações entre as coordenadas (scores) da ACP e a altitude e distância em relação ao oceano. Os sítios dos Aparados da Serra Geral e os da Serra Mantiqueira não foram incluídos na $\mathrm{ACP}$, pois as densidades das espécies não atenderam requisitos de normalidade, mesmo após a transformação os dados.

\section{Resultados}

\section{Estrutura horizontal da FODAM na Serra da Prata}

Foram amostrados 424 indivíduos arbóreos incluídos em 37 espécies, 16 gêneros e 17 famílias botânicas (Tab. 1). Myrtaceae apresentou 17 espécies pertencentes a oito gêneros. Esta família contribuiu com $50 \%$ da densidade arbórea estimada, somando aproximadamente $42 \%$ da importância fitossociológica. Drimys angustifolia (Winteraceae) foi a mais importante devido, primordialmente, ao maior porte de seus indivíduos (valor máximo de $28 \mathrm{~cm}$ de DAP, com $6,8 \mathrm{~m}$ de altura).

Seguindo a ordem de porcentagem de importância, Myrceugenia seriatoramosa e Siphoneugena reitzii, ambas da família Myrtaceae, foram as espécies que se destacaram respectivamente pela maior frequência e maior densidade de indivíduos acima do PAP estabelecido. Ilex microdonta, espécie que segundo Roderjan (1994) e Koehler et al. (2002) tipifica a floresta altomontana na Serra do Mar no Paraná, ficou em quarto lugar em importância estrutural, apresentando maior dominância relativa do que densidade relativa, indicando também um porte relativamente grande de seus indivíduos (valor máximo de $23 \mathrm{~cm}$ de DAP, com $6 \mathrm{~m}$ de altura). As seis espécies mais importantes somam $53 \%$ da porcentagem de importância (Tab. 1).

Numa breve comparação entre as parcelas entre as faces leste e oeste, a espécie M. seriatoramosa apresentou a maior porcentagem de importância (PI) na face leste, enquanto 
Tabela 1. Parâmetros fitossociológicos das espécies arbóreas ( $\mathrm{PAP} \geq 10 \mathrm{~cm}$ ) dos trechos de Floresta Ombrófila Densa Altomontana amostrados na Serra da Prata, município de Paranaguá, PR. Legenda: DA - densidade absoluta (ind/ha); DR - densidade relativa (\%); DoA - dominância absoluta ( $\left.\mathrm{m}^{2} / \mathrm{ha}\right) ;$ DoR - dominância relativa (\%); FA - frequencia absoluta; FR - frequencia relativa (\%); PI - porcentagem de importância (\%)

\begin{tabular}{|c|c|c|c|c|c|c|c|}
\hline Espécie & DA & DR & DoA & DoR & FA & FR & PI \\
\hline Drimys angustifolia & 250,0 & 7,1 & 5,72 & 19,42 & 58,3 & 6,0 & 10,8 \\
\hline Myrceugenia seriatoramosa & 408,3 & 11,6 & 3,58 & 12,15 & 79,2 & 8,1 & 10,6 \\
\hline Siphoneugena reitzii & 458,3 & 13,0 & 1,62 & 5,50 & 75,0 & 7,7 & 8,7 \\
\hline Ilex microdonta & 166,7 & 4,7 & 3,65 & 12,39 & 62,5 & 6,4 & 7,8 \\
\hline Ocotea porosa & 216,7 & 6,1 & 2,79 & 9,49 & 70,8 & 7,2 & 7,6 \\
\hline Ilex chamaedrifolia & 241,7 & 6,8 & 2,12 & 7,19 & 70,8 & 7,2 & 7,1 \\
\hline Myrcia pulchra & 358,3 & 10,1 & 1,17 & 3,99 & 54,2 & 5,5 & 6,6 \\
\hline Citronella paniculata & 283,3 & 8,0 & 1,13 & 3,83 & 62,5 & 6,4 & 6,1 \\
\hline Eugenia neomyrtifolia & 166,7 & 4,7 & 0,94 & 3,20 & 58,3 & 6,0 & 4,6 \\
\hline Handroanthus catarinensis & 133,3 & 3,8 & 0,62 & 2,09 & 66,7 & 6,8 & 4,2 \\
\hline Coccoloba persicaria & 100,0 & 2,8 & 0,75 & 2,56 & 37,5 & 3,8 & 3,1 \\
\hline Symplocos corymboclados & 75,0 & 2,1 & 0,82 & 2,78 & 25,0 & 2,6 & 2,5 \\
\hline Eugenia nutans & 58,3 & 1,7 & 0,89 & 3,02 & 20,8 & 2,1 & 2,3 \\
\hline Symplocos bidana & 41,7 & 1,2 & 0,80 & 2,70 & 20,8 & 2,1 & 2,0 \\
\hline Myrcia richardiana & 75,0 & 2,1 & 0,26 & 0,87 & 29,2 & 3,0 & 2,0 \\
\hline Myrceugenia franciscensis & 66,7 & 1,9 & 0,15 & 0,51 & 25,0 & 2,6 & 1,7 \\
\hline Weinmannia humilis & 83,3 & 2,4 & 0,35 & 1,20 & 4,2 & 0,4 & 1,3 \\
\hline Ternstroemia brasiliensis & 41,7 & 1,2 & 0,16 & 0,55 & 20,8 & 2,1 & 1,3 \\
\hline Eugenia sclerocalyx & 41,7 & 1,2 & 0,19 & 0,66 & 16,7 & 1,7 & 1,2 \\
\hline Tibouchina reitzii & 25,0 & 0,7 & 0,29 & 1,00 & 12,5 & 1,3 & 1,0 \\
\hline Pimenta pseudocaryophyllus & 16,7 & 0,5 & 0,45 & 1,52 & 8,3 & 0,9 & 1,0 \\
\hline Plinia cordifolia & 33,3 & 0,9 & 0,08 & 0,28 & 12,5 & 1,3 & 0,8 \\
\hline Roupala rhombifolia & 25,0 & 0,7 & 0,11 & 0,39 & 12,5 & 1,3 & 0,8 \\
\hline Rudgea parquioides & 25,0 & 0,7 & 0,06 & 0,22 & 12,5 & 1,3 & 0,7 \\
\hline Myrceugenia sp. & 33,3 & 0,9 & 0,06 & 0,19 & 8,3 & 0,9 & 0,7 \\
\hline Myrsine altomontana & 16,7 & 0,5 & 0,04 & 0,14 & 8,3 & 0,9 & 0,5 \\
\hline Cyathea sp. (feto arborescente) & 8,3 & 0,2 & 0,17 & 0,56 & 4,2 & 0,4 & 0,4 \\
\hline Persea willdenovii & 8,3 & 0,2 & 0,16 & 0,54 & 4,2 & 0,4 & 0,4 \\
\hline Myrceugenia pilotantha & 8,3 & 0,2 & 0,10 & 0,35 & 4,2 & 0,4 & 0,3 \\
\hline Blepharocalyx salicifolius & 8,3 & 0,2 & 0,05 & 0,17 & 4,2 & 0,4 & 0,3 \\
\hline Eugenia handroana & 8,3 & 0,2 & 0,05 & 0,17 & 4,2 & 0,4 & 0,3 \\
\hline Prunus brasiliensis & 8,3 & 0,2 & 0,03 & 0,11 & 4,2 & 0,4 & 0,3 \\
\hline Drimys brasiliensis & 8,3 & 0,2 & 0,03 & 0,09 & 4,2 & 0,4 & 0,3 \\
\hline Gomidesia sellowianna & 8,3 & 0,2 & 0,02 & 0,05 & 4,2 & 0,4 & 0,2 \\
\hline Myrceugenia euosma & 8,3 & 0,2 & 0,01 & 0,05 & 4,2 & 0,4 & 0,2 \\
\hline Maytenus glaucescens & 8,3 & 0,2 & 0,01 & 0,04 & 4,2 & 0,4 & 0,2 \\
\hline MYRTACEAE indet. 1 & 8,3 & 0,2 & 0,01 & 0,04 & 4,2 & 0,4 & 0,2 \\
\hline TOTAL & 3533,3 & 100,0 & 29,44 & 100,00 & 979,2 & 100,0 & 100,0 \\
\hline
\end{tabular}


que S. reitzii ficou com o oitavo maior PI. A posição na análise fitossociológica entre essas duas espécies se inverteu avaliando a face oeste. Na face leste foram amostrados indivíduos de Blepharocalyx salicifolius e Myrcia hartwegiana, espécies que, segundo Koehler et al. (2002), são facilmente encontradas na Floresta Ombrófila Mista, descartando-se a possibilidade exposta por esses autores da sua não ocorrência em montanhas na situação de menor continentalidade (24 km do oceano). Muitas espécies foram encontradas somente numa das faces analisadas, indicando que, apesar da estrutura simplificada da floresta altomontana, há certa heterogeneidade de espécies dominando sua composição estrutural (ver detalhes em Scheer 2010).

\section{Estrutura horizontal da FODAM na Serra do Ibitiraquire}

Nas quatro montanhas amostradas nesta serra, foram medidos 552 indivíduos arbóreos pertencentes a 26 espécies, a 19 gêneros e a 15 famílias botânicas (Tab. 2). A família Myrtaceae foi representada por nove espécies pertencentes a quatro gêneros, somando $46 \%$ da densidade arbórea, contribuindo com aproximadamente $38 \%$ da importância fitossociológica. As quatro espécies mais importantes foram as mesmas que as da Serra da Prata, porém na ordem inversa. I. microdonta apresentou a maior importância devido aos altos valores de densidade, dominância e frequência. Na sequência de porcentagem de importância, S. reitzii foi a espécie com maior densidade de indivíduos e $M$. seriatoramosa foi a única presente em todas as unidades amostrais. Ao contrário da Serra da Prata, D. angustifolia teve o quarto maior PI, invertendo a posição de mais importante estruturalmente com I. microdonta, indicando também um porte relativamente maior de seus indivíduos (indivíduos alcançando $27 \mathrm{~cm}$ de DAP, com 7,2 $\mathrm{m}$ de altura). As quatro espécies mais importantes somam $57 \%$ do PI.

Tabela 2. Parâmetros fitossociológicos das espécies arbóreas (PAP $\geq 10 \mathrm{~cm}$ ) dos trechos de Floresta Ombrófila Densa Altomontana amostrados na Serra do Ibitiraquire, município de Campina Grande do Sul, PR. Legenda: DA - densidade absoluta (ind/ha); DR - densidade relativa (\%); DoA - dominância absoluta ( ${ }^{2} /$ ha); DoR - dominância relativa (\%); FA - frequencia absoluta; FR - frequencia relativa (\%); PI - porcentagem de importância (\%)

\begin{tabular}{|c|c|c|c|c|c|c|c|}
\hline Espécie & DA & $\mathrm{DR}$ & DoA & DoR & FA & FR & PI \\
\hline Ilex microdonta & 766,7 & 16,7 & 9,09 & 22,57 & 95,8 & 11,4 & 16,9 \\
\hline Siphoneugena reitzii & 950,0 & 20,7 & 6,33 & 15,71 & 91,7 & 11,0 & 15,8 \\
\hline Myrceugenia seriatoramosa & 766,7 & 16,7 & 5,05 & 12,53 & 100,0 & 11,9 & 13,7 \\
\hline Drimys angustifolia & 333,3 & 7,3 & 7,63 & 18,94 & 58,3 & 7,0 & 11,1 \\
\hline Symplocos corymboclados & 225,0 & 4,9 & 3,34 & 8,29 & 58,3 & 7,0 & 6,7 \\
\hline Ocotea porosa & 250,0 & 5,4 & 2,44 & 6,05 & 66,7 & 8,0 & 6,5 \\
\hline Ilex chamaedrifolia & 208,3 & 4,5 & 1,42 & 3,52 & 50,0 & 6,0 & 4,7 \\
\hline Handroanthus catarinensis & 266,7 & 5,8 & 0,70 & 1,74 & 37,5 & 4,5 & 4,0 \\
\hline Citronella paniculata & 116,7 & 2,5 & 0,53 & 1,32 & 50,0 & 6,0 & 3,3 \\
\hline Eugenia neomyrtifolia & 175,0 & 3,8 & 0,42 & 1,04 & 41,7 & 5,0 & 3,3 \\
\hline Roupala rhombifolia & 83,3 & 1,8 & 0,68 & 1,69 & 25,0 & 3,0 & 2,2 \\
\hline Myrceugenia ovata & 50,0 & 1,1 & 0,30 & 0,75 & 20,8 & 2,5 & 1,4 \\
\hline Weinmannia humilis & 41,7 & 0,9 & 0,55 & 1,37 & 16,7 & 2,0 & 1,4 \\
\hline Symplocos incrassata & 66,7 & 1,5 & 0,53 & 1,33 & 12,5 & 1,5 & 1,4 \\
\hline Eugenia handroana & 66,7 & 1,5 & 0,13 & 0,32 & 20,8 & 2,5 & 1,4 \\
\hline Clethra uleana & 33,3 & 0,7 & 0,20 & 0,48 & 16,7 & 2,0 & 1,1 \\
\hline Eugenia sclerocalyx & 25,0 & 0,5 & 0,13 & 0,31 & 12,5 & 1,5 & 0,8 \\
\hline Myrsine altomontana & 33,3 & 0,7 & 0,04 & 0,10 & 12,5 & 1,5 & 0,8 \\
\hline Maytenus urbaniana & 25,0 & 0,5 & 0,19 & 0,48 & 8,3 & 1,0 & 0,7 \\
\hline Blepharocalyx salicifolius & 25,0 & 0,5 & 0,14 & 0,36 & 8,3 & 1,0 & 0,6 \\
\hline Myrceugenia sp. & 25,0 & 0,5 & 0,06 & 0,14 & 8,3 & 1,0 & 0,6 \\
\hline Persea willdenovii & 25,0 & 0,5 & 0,21 & 0,51 & 4,2 & 0,5 & 0,5 \\
\hline Myrceugenia franciscensis & 16,7 & 0,4 & 0,04 & 0,10 & 8,3 & 1,0 & 0,5 \\
\hline Daphnopsis sellowiana & 8,3 & 0,2 & 0,10 & 0,24 & 4,2 & 0,5 & 0,3 \\
\hline Symphyopappus lymansmithii & 8,3 & 0,2 & 0,02 & 0,05 & 4,2 & 0,5 & 0,2 \\
\hline Xylosma pseudosalzmanii & 8,3 & 0,2 & 0,02 & 0,05 & 4,2 & 0,5 & 0,2 \\
\hline TOTAL & 4600,0 & 100,0 & 40,29 & 100,00 & 837,5 & 100,0 & 100,0 \\
\hline
\end{tabular}


Assim como realizado para a Serra da Prata, breves estratificações do conjunto de parcelas, no caso pelas exposições norte e sul e por posições superior e inferior da encosta (dentro do patamar altomontano), indicaram que muitas espécies foram amostradas em apenas uma das faces ou posições (ver detalhes em Scheer 2010). Os valores de densidade e área basal pouco se alteraram na análise com a estratificação dos trechos, tanto por posição da encosta quanto por exposição, indicando que a estrutura arbórea destes locais deve sofrer maior influência das feições geomórficas e, consequentemente, dos solos.

\section{Estrutura horizontal da FODAM na Serra da Igreja}

Foram amostrados 587 indivíduos arbóreos, pertencentes a 34 espécies, 25 gêneros e 19 famílias. As cinco espécies mais importantes perfazem mais da metade da porcentagem de importância da comunidade, somando 58,3\% (Tab. 3). A família Myrtaceae foi a mais bem representada, com 11 espécies e seis gêneros (33,6\% da população arbórea e 30\% de PI), seguida de Lauraceae, com quatro espécies. S. reitzii apresentou a maior densidade e a segunda maior dominância da comunidade, destacando-se como a espécie mais importante em termos de porcentagem de importância, apesar da diferença para $D$. angustifolia ser muito pequena. Apesar desta espécie apresentar densidade consideravelmente menor, é representada por indivíduos de maior porte (valor máximo de $73 \mathrm{~cm}$ de DAP, com 6,1 m de altura), resultando em um alto valor de dominância. I. microdonta novamente está entre as principais espécies dessa comunidade altomontana.

\section{Estrutura horizontal da FODAM na Serra Gigante}

$\mathrm{Na}$ Serra Gigante foram mensurados 786 indivíduos, pertencentes a 41 espécies, 27 gêneros e 18 famílias (Tab. 4). As quatro espécies mais importantes somaram $51,6 \%$ da porcentagem de importância da comunidade. Novamente a família Myrtaceae apresentou o maior número de espécies (11), com seis gêneros, perfazendo $57,6 \%$ da comunidade arbórea e 53,5\% da porcentagem de importância. Myrcia pulchra apresentou o maior porcentual de importância devido à sua maior densidade e dominância (valor máximo de $81,4 \mathrm{~cm}$ de PAP, com $7 \mathrm{~m}$ de altura). As espécies Myrcia dicrophylla, Ouratea vaccinioides, Ternstroemia brasiliensis e Ilex integerrima apresentaram grande participação na estrutura da comunidade (Tab. 4), fato ainda não observado em outras montanhas.

O maior número de espécies arbóreas mensuradas na floresta altomontana na Serra Gigante pode estar relacionado a sua menor altitude e gradiente altitudinal, uma vez que se observa a inclusão de espécies de ocorrência mais comum nas florestas montanas (I. integerrima, Ilex taubertiana, Ouratea vaccinioides, Coussarea contracta, Weinmannia paullinifolia, entre outras).

\section{Distribuições diamétricas ehipsométricas das florestas estudadas}

A distribuição das classes diamétricas (Fig. 2) evidencia uma típica distribuição em "J invertido", com a maioria dos indivíduos concentrada na primeira classe $(3,2$ a $6,8 \mathrm{~cm}$ de DAP), com destaque para a maior quantidade observada na Serra Gigante, a de menor altitude.

Através da distribuição por classes de altura dos indivíduos arbóreos (Fig. 3) pode-se notar que as comunidades altomontanas estudadas são baixas, com a maioria das árvores entre 4 e $5 \mathrm{~m}$ de altura, com pouquíssimos indivíduos alcançando $8 \mathrm{~m}$.

\section{Florística, estrutura e diversidade arbórea das serras amostradas}

Nas 96 parcelas $\left(4800 \mathrm{~m}^{2}\right)$ foram amostrados 2294 indivíduos arbóreos (PAP $\geq 10 \mathrm{~cm}$ ) pertencentes a 29 famílias, 43 gêneros e 78 táxons, sendo 58 determinações em nível de espécie (Fig. 4). A altura média dos indivíduos foi de $4,8 \mathrm{~m}$, o diâmetro à altura do peito - DAP de $7,3 \mathrm{~cm}$ (PAP de 22,9 cm), a densidade de $4779 \mathrm{ind} / \mathrm{ha} \mathrm{e}$ a área basal de $33,5 \mathrm{~m}^{2} / \mathrm{ha}$. Conforme já comentado, a amostragem na Serra Gigante resultou na maior riqueza de espécies (41), seguida pelos valores encontrados nas serras da Prata (37), da Igreja (34) e do Ibitiraquire (26). Foram observadas apenas fracas relações lineares negativas significativas entre o número de espécies por parcela e a altitude $\left(Y=14,9332-0,0395415 \times\right.$ Alt, $\left.R^{2}=0,19 ; p<0,01\right)$ considerando as parcelas das quatro serras e quando foram consideradas só as parcelas na Serra do Ibitiraquire $(Y=$ $27,1086-0,0113362 \times$ Alt, $\left.R^{2}=0,30 ; p<0,01\right)$.

$\mathrm{O}$ índice de diversidade de Shannon foi significativamente maior na Serra da Prata do que nas Serras da Igreja e Gigante ( $t$ de Hutcheson, $p<0,05)$, sendo que estas apresentaram índices significativamente maiores que a Serra do Ibitiraquire ( $t$ de Hutcheson, $p<0,05$, Tab. 6).

$\mathrm{Na}$ Fig. 4 e nas Tabs. 1 a 4 , onde constam as espécies das comunidades arbóreas altomontanas amostradas em cada serra, de acordo com a porcentagem de importância estrutural, destaca-se Siphoneugena reitzii, que em todas as áreas esteve entre as três mais importantes (em média $14 \%$ da porcentagem de importância - PI). Drimys angustifolia e Ilex microdonta estão entre as quatro mais importantes em três áreas (em média 9\% do PI), exceto na Serra Gigante.

Na Fig. 4, Myrcia pulchra aparece como a quarta espécie mais importante ( $8 \%$ do PI) devido a sua grande dominância e abundância na Serra Gigante (serra de menor altitude, Tab. 4). Myrceugenia seriatoramosa foi elencada como a quinta espécie mais importante (6\% do $\mathrm{PI})$, com grande participação na estrutura das florestas altomontanas nas serras de maior altitude. Apenas sete espécies foram amostradas em todas as quatro serras: $S$. reitzii, I. microdonta, Ocotea porosa, Citronella paniculata, Ilex chamaedrifolia, Handroanthus catarinensis e Symplocos corymboclados.

O dendrograma que relaciona a porcentagem de importância evidencia um grupo que inclui as serras do Ibitiraquire, Prata e da Igreja e isola a Serra Gigante (Fig. 5). 
Tabela 3. Parâmetros fitossociológicos das espécies arbóreas (PAP $\geq 10 \mathrm{~cm}$ ) dos trechos de Floresta Ombrófila Densa Altomontana amostrados na Serra da Igreja, município de Morretes, PR. Legenda: DA - densidade absoluta (ind/ha); DR - densidade relativa (\%); DoA - dominância absoluta (m²/ha); DoR - dominância relativa (\%); FA - frequencia absoluta; FR - frequencia relativa (\%); PI - porcentagem de importância (\%)

\begin{tabular}{|c|c|c|c|c|c|c|c|}
\hline Espécie & $\mathrm{DA}$ & DR & DoA & DoR & FA & FR & PI \\
\hline Siphoneugena reitzii & 944,0 & 20,1 & 4,80 & 15,74 & 92,0 & 9,5 & 15,1 \\
\hline Drimys angustifolia & 600,0 & 12,8 & 6,83 & 22,38 & 92,0 & 9,5 & 14,9 \\
\hline Ilex microdonta & 432,0 & 9,2 & 4,31 & 14,11 & 76,0 & 7,8 & 10,4 \\
\hline Handroanthus catarinensis & 536,0 & 11,4 & 2,35 & 7,69 & 84,0 & 8,6 & 9,3 \\
\hline Citronella paniculata & 544,0 & 11,6 & 1,67 & 5,47 & 88,0 & 9,1 & 8,7 \\
\hline Weinmannia humilis & 296,0 & 6,3 & 2,54 & 8,32 & 80,0 & 8,2 & 7,6 \\
\hline Myrceugenia franciscensis & 240,0 & 5,1 & 1,56 & 5,10 & 60,0 & 6,2 & 5,5 \\
\hline Myrcia pulchra & 184,0 & 3,9 & 0,58 & 1,91 & 56,0 & 5,8 & 3,9 \\
\hline Ilex chamaedrifolia & 136,0 & 2,9 & 1,07 & 3,51 & 44,0 & 4,5 & 3,6 \\
\hline Tibouchina reitzii & 144,0 & 3,1 & 1,04 & 3,41 & 32,0 & 3,3 & 3,3 \\
\hline Ternstroemia brasiliensis & 128,0 & 2,7 & 0,33 & 1,07 & 40,0 & 4,1 & 2,6 \\
\hline Ocotea porosa & 64,0 & 1,4 & 1,03 & 3,37 & 24,0 & 2,5 & 2,4 \\
\hline Myrceugenia seriatoramosa & 56,0 & 1,2 & 0,31 & 0,99 & 28,0 & 2,9 & 1,7 \\
\hline Podocarpus sellowii & 56,0 & 1,2 & 0,19 & 0,62 & 28,0 & 2,9 & 1,6 \\
\hline Drimys brasiliensis & 48,0 & 1,0 & 0,29 & 0,96 & 20,0 & 2,1 & 1,4 \\
\hline Myrcia hartwegiana & 40,0 & 0,9 & 0,16 & 0,52 & 16,0 & 1,7 & 1,0 \\
\hline MYRTACEAE indet. 1 & 48,0 & 1,0 & 0,14 & 0,45 & 12,0 & 1,2 & 0,9 \\
\hline Pimenta pseudocaryophyllus & 32,0 & 0,7 & 0,08 & 0,27 & 16,0 & 1,7 & 0,9 \\
\hline Ocotea vaccinioides & 16,0 & 0,3 & 0,24 & 0,79 & 8,0 & 0,8 & 0,7 \\
\hline Symphyopappus lymansmithii & 24,0 & 0,5 & 0,05 & 0,15 & 12,0 & 1,2 & 0,6 \\
\hline Ocotea pulchella & 8,0 & 0,2 & 0,34 & 1,11 & 4,0 & 0,4 & 0,6 \\
\hline Myrcia richardiana & 16,0 & 0,3 & 0,07 & 0,24 & 8,0 & 0,8 & 0,5 \\
\hline Agarista niederleinii & 16,0 & 0,3 & 0,05 & 0,16 & 8,0 & 0,8 & 0,4 \\
\hline Weinmannia paullinifolia & 8,0 & 0,2 & 0,10 & 0,34 & 4,0 & 0,4 & 0,3 \\
\hline Myrsine cf. umbellata & 8,0 & 0,2 & 0,07 & 0,21 & 4,0 & 0,4 & 0,3 \\
\hline Eugenia sp. & 8,0 & 0,2 & 0,06 & 0,19 & 4,0 & 0,4 & 0,3 \\
\hline Indeterminada 1 & 8,0 & 0,2 & 0,05 & 0,18 & 4,0 & 0,4 & 0,3 \\
\hline Persea sp. & 8,0 & 0,2 & 0,04 & 0,15 & 4,0 & 0,4 & 0,2 \\
\hline Symplocos corymboclados & 8,0 & 0,2 & 0,04 & 0,14 & 4,0 & 0,4 & 0,2 \\
\hline MYRTACEAE indet. 2 & 8,0 & 0,2 & 0,04 & 0,13 & 4,0 & 0,4 & 0,2 \\
\hline Xylosma pseudosalzmanii & 8,0 & 0,2 & 0,04 & 0,12 & 4,0 & 0,4 & 0,2 \\
\hline Indeterminada 1 & 8,0 & 0,2 & 0,03 & 0,10 & 4,0 & 0,4 & 0,2 \\
\hline Rhamnus sphaerosperma & 8,0 & 0,2 & 0,03 & 0,09 & 4,0 & 0,4 & 0,2 \\
\hline Daphnopsis cf. sellowiana & 8,0 & 0,2 & 0,01 & 0,03 & 4,0 & 0,4 & 0,2 \\
\hline TOTAL & 4696,0 & 100,0 & 30,52 & 100,00 & 972,0 & 100,0 & 100,0 \\
\hline
\end{tabular}

\section{Florística, estrutura e diversidade arbórea da Serra do Mar paranaense}

Agrupando-se os dados deste estudo aos das demais subserras paranaenses, obteve-se uma matriz com 109 táxons, sendo 75 diferentes determinações em nível de espécie, pertencentes a 29 famílias botânicas (Fig. 6). De acordo com os 11 levantamentos nas nove serras, as cinco espécies que se destacam com os maiores valores de impor- tância na estrutura das florestas altomontanas da Serra do Mar paranaense foram: I. microdonta (PI $=18,1 \%$ do total), S. reitzii $(\mathrm{PI}=9,6 \%), D$. angustifolia $(\mathrm{PI}=7,8 \%)$, O. porosa $(\mathrm{PI}=5,7 \%)$ e I. chamaedrifolia $(\mathrm{PI}=4,8 \%)$, somando em torno de $45 \%$ do PI. Dessas, somente I. microdonta e $O$. porosa foram amostradas em todos os levantamentos. As 25 espécies subsequentes representaram outros $45 \%$ do PI e as 79 espécies/táxons restantes apenas 10\% do PI. 
Tabela 4. Parâmetros fitossociológicos das espécies arbóreas $(\mathrm{PAP} \geq 10 \mathrm{~cm}$ ) dos trechos de Floresta Ombrófila Densa Altomontana amostrados na Serra Gigante, município de Guaraqueçaba, PR. Legenda: DA - densidade absoluta (ind/ha); DR - densidade relativa (\%); DoA - dominância absoluta ( $\mathrm{m}^{2} / \mathrm{ha}$ ); DoR - dominância relativa (\%); FA - frequencia absoluta; FR - frequencia relativa (\%); PI - porcentagem de importância (\%)

\begin{tabular}{|c|c|c|c|c|c|c|c|}
\hline Espécie & DA & $\mathrm{DR}$ & DoA & DoR & $\mathrm{FA}$ & FR & PI \\
\hline Myrcia pulchra & 1472,0 & 23,4 & 9,82 & 33,13 & 96,0 & 8,8 & 21,6 \\
\hline Siphoneugena reitzii & 1024,0 & 16,3 & 5,57 & 18,80 & 96,0 & 8,8 & 14,6 \\
\hline Ouratea vaccinioides & 720,0 & 11,5 & 1,78 & 6,00 & 96,0 & 8,8 & 8,8 \\
\hline Myrcia dicrophylla & 528,0 & 8,4 & 1,26 & 4,27 & 80,0 & 7,3 & 6,7 \\
\hline Pimenta pseudocaryophyllus & 360,0 & 5,7 & 1,53 & 5,17 & 68,0 & 6,2 & 5,7 \\
\hline Ternstroemia brasiliensis & 336,0 & 5,3 & 0,88 & 2,98 & 68,0 & 6,2 & 4,9 \\
\hline Ocotea porosa & 296,0 & 4,7 & 1,04 & 3,50 & 68,0 & 6,2 & 4,8 \\
\hline Ocotea vaccinioides & 232,0 & 3,7 & 1,30 & 4,40 & 60,0 & 5,5 & 4,5 \\
\hline Ilex integerrima & 184,0 & 2,9 & 1,68 & 5,67 & 44,0 & 4,0 & 4,2 \\
\hline Podocarpus sellowii & 128,0 & 2,0 & 0,93 & 3,13 & 40,0 & 3,7 & 2,9 \\
\hline Ilex chamaedrifolia & 152,0 & 2,4 & 0,41 & 1,40 & 48,0 & 4,4 & 2,7 \\
\hline Citronella paniculata & 88,0 & 1,4 & 0,22 & 0,74 & 40,0 & 3,7 & 1,9 \\
\hline Clethra scabra & 88,0 & 1,4 & 0,51 & 1,71 & 28,0 & 2,6 & 1,9 \\
\hline Blepharocalyx salicifolius & 64,0 & 1,0 & 0,40 & 1,36 & 32,0 & 2,9 & 1,8 \\
\hline Drimys brasiliensis & 88,0 & 1,4 & 0,26 & 0,89 & 32,0 & 2,9 & 1,7 \\
\hline Eugenia cf. oeidocarpa & 64,0 & 1,0 & 0,15 & 0,50 & 28,0 & 2,6 & 1,4 \\
\hline Ilex taubertiana & 56,0 & 0,9 & 0,21 & 0,72 & 16,0 & 1,5 & 1,0 \\
\hline Inga barbata & 56,0 & 0,9 & 0,09 & 0,30 & 20,0 & 1,8 & 1,0 \\
\hline Eugenia handroana & 64,0 & 1,0 & 0,28 & 0,93 & 8,0 & 0,7 & 0,9 \\
\hline Ilex microdonta & 16,0 & 0,3 & 0,27 & 0,91 & 8,0 & 0,7 & 0,6 \\
\hline Myrsine altomontana & 24,0 & 0,4 & 0,10 & 0,35 & 12,0 & 1,1 & 0,6 \\
\hline Handroanthus catarinensis & 40,0 & 0,6 & 0,11 & 0,36 & 8,0 & 0,7 & 0,6 \\
\hline Coussarea contracta & 16,0 & 0,3 & 0,05 & 0,18 & 8,0 & 0,7 & 0,4 \\
\hline Symplocos corymboclados & 16,0 & 0,3 & 0,02 & 0,07 & 8,0 & 0,7 & 0,4 \\
\hline Indeterminada 1 & 16,0 & 0,3 & 0,13 & 0,43 & 4,0 & 0,4 & 0,4 \\
\hline Weinmannia paullinifolia & 16,0 & 0,3 & 0,02 & 0,06 & 8,0 & 0,7 & 0,4 \\
\hline Piptocarpa densifolia & 8,0 & 0,1 & 0,13 & 0,44 & 4,0 & 0,4 & 0,3 \\
\hline Persea alba & 8,0 & 0,1 & 0,09 & 0,31 & 4,0 & 0,4 & 0,3 \\
\hline Indeterminada 2 & 8,0 & 0,1 & 0,08 & 0,26 & 4,0 & 0,4 & 0,3 \\
\hline Myrsine umbelata & 16,0 & 0,3 & 0,04 & 0,12 & 4,0 & 0,4 & 0,3 \\
\hline Eugenia melanogyna & 16,0 & 0,3 & 0,02 & 0,07 & 4,0 & 0,4 & 0,2 \\
\hline Laplacea fruticosa & 8,0 & 0,1 & 0,05 & 0,17 & 4,0 & 0,4 & 0,2 \\
\hline Eugenia nutans & 16,0 & 0,3 & 0,01 & 0,02 & 4,0 & 0,4 & 0,2 \\
\hline Myrceugenia euosma & 8,0 & 0,1 & 0,04 & 0,14 & 4,0 & 0,4 & 0,2 \\
\hline MYRTACEAE indet. 1 & 8,0 & 0,1 & 0,03 & 0,09 & 4,0 & 0,4 & 0,2 \\
\hline Daphnopsis fasciculata & 8,0 & 0,1 & 0,01 & 0,05 & 4,0 & 0,4 & 0,2 \\
\hline Symplocos sp. & 8,0 & 0,1 & 0,01 & 0,04 & 4,0 & 0,4 & 0,2 \\
\hline ASTERACEAE indet. 1 & 8,0 & 0,1 & 0,01 & 0,03 & 4,0 & 0,4 & 0,2 \\
\hline Agarista sp. & 8,0 & 0,1 & 0,01 & 0,03 & 4,0 & 0,4 & 0,2 \\
\hline Matayba guianensis & 8,0 & 0,1 & 0,01 & 0,02 & 4,0 & 0,4 & 0,2 \\
\hline Indeterminada 3 & 8,0 & 0,1 & 0,01 & 0,02 & 4,0 & 0,4 & 0,2 \\
\hline TOTAL & 6288,0 & 100,0 & 29,63 & 100,00 & 1092,0 & 100,0 & 100,0 \\
\hline
\end{tabular}




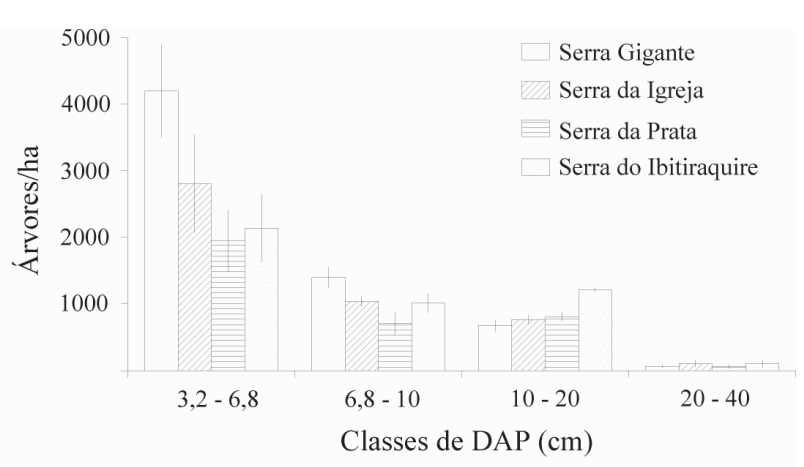

Figura 2. Distribuição diamétrica dos indivíduos arbóreos nas florestas altomontanas amostradas em quatro subserras do Paraná. As linhas verticais representam os desvios padrões. DAP - diâmetro à altura do peito

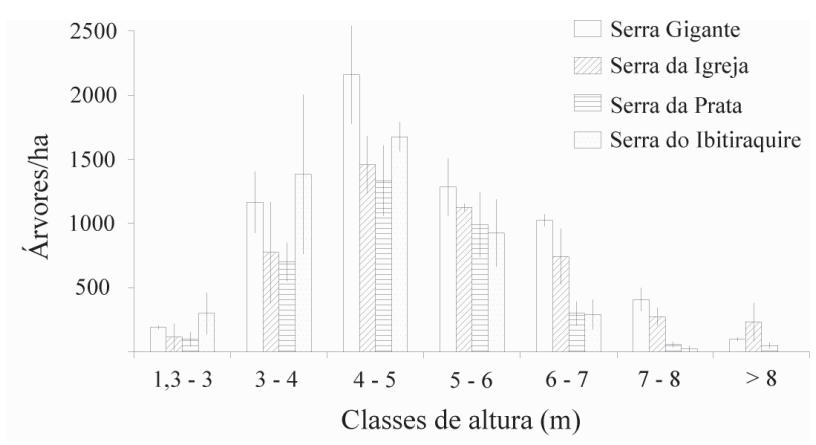

Figura 3. Distribuição hipsométrica dos indivíduos arbóreos nas florestas altomontanas amostradas em quatro subserras do Paraná. As linhas verticais representam os desvios padrões

Myrtaceae e Aquifoliaceae contribuem com $61 \%$ da importância fitossociológica da comunidade arbórea altomontana amostrada na Serra do Mar no Paraná (Fig. 7). Winteraceae, Lauraceae, Bignoniaceae, Cunoniaceae e Cardiopteridaceae também apresentam uma importante participação, com valores de importância de 8, 7, 4, 3 e $3 \%$, respectivamente.

\section{Comparações com outras serras do Sul e Sudeste brasileiro}

O dendrograma resultante da análise de agrupamento pela porcentagem de importância das espécies na estrutura arbórea das florestas altomontanas das nove serras (subserras) do Complexo Serra do Mar no Paraná e de florestas ombrófilas altomontanas ocorrentes nos Aparados da Serra Geral (SC) e na Serra da Mantiqueira (MG), destacou dois grandes grupos (Fig. 8). O primeiro grupo é composto por todos os sítios localizados na Serra do Mar no Paraná e os das Serras dos Aparados da Serra Geral (serras da Igreja e do Rio do Rastro) em Santa Catarina, onde destaca-se a proximidade das serras do Ibitiraquire e da Prata, seguida das serras da Igreja (PR) e do Marumbi. Outro subgrupo de elevada similaridade é composto pelos sítios altomontanos estudados na Serra da Baitaca, na Serra da Graciosa (Morro Mãe Catira) e na Serra do Marumbi (Morro do Vigia), os quais são em serras próximas e vizinhas, de altitudes similares. $\mathrm{O}$ segundo grande grupo é composto apenas pelas flores-

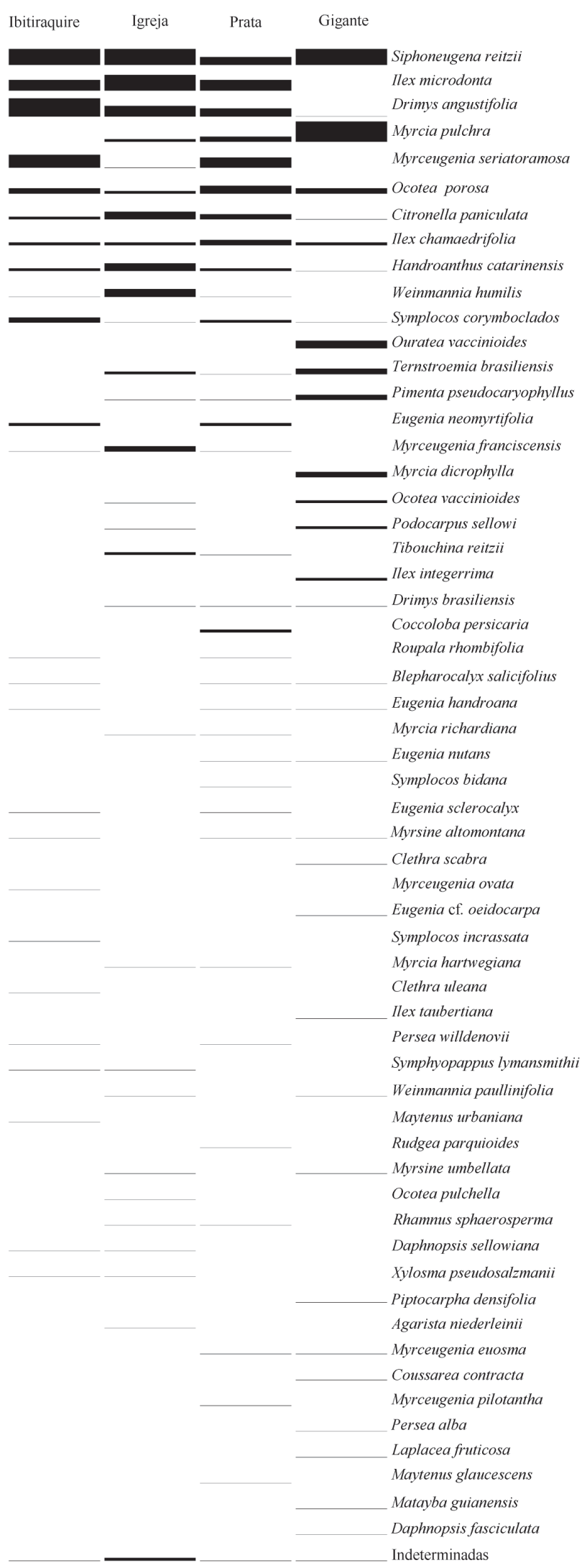

Porcentagem de importância estrutural (\%)

Figura 4. Espécies em ordem decrescente de porcentagem de importância estrutural nas florestas altomontanas amostradas em quatro subserras do Paraná 
Porcentagem de Importância

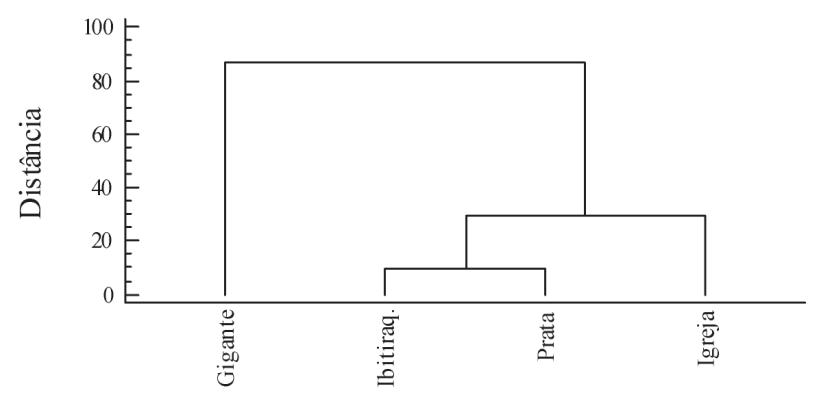

Figura 5. Dendrograma com base nos valores de importância das espécies amostradas nas florestas altomontanas em quatro subserras do Paraná

tas altomontanas amostradas na Serra da Mantiqueira (França e Stehmann 2004 e Meireles et al. 2008) (Fig. 8).

As três componentes principais explicaram $69,1 \%$ da variação nos dados de densidade das 30 espécies mais importantes na estrutura arbórea dos 11 levantamentos em florestas altomontanas paranaenses (Tab. 5). Os dois sítios na Serra da Baitaca (1 e 2) e o do Morro do Vigia apresentaram contribuições importantes no primeiro eixo, o qual explicou $40,3 \%$ da variação. As Serras da Prata, Igreja e Ibitiraquire foram importantes para o segundo eixo $(17,1 \%)$ e os sítios nas Serras Gigante, da Graciosa e do Araçatuba foram importantes para o terceiro eixo (11,7\%). As coordenadas do primeiro e terceiro eixos apresentaram correlação positiva com a altitude (Tab. 6).

Tabela 5. Resultados da análise de componentes principais com base nas densidades de indivíduos das 30 espécies com maiores valores de importância entre os 11 levantamentos na Serra do Mar paranaense. Contribuições consideradas importantes são as maiores do que 0,6 (em negrito). $R s=$ coeficientes de correlação de Spearman $(p<0,05 ; \mathrm{n}=11)$ entre as coordenadas das amostras da ACP, a altitude e distância das florestas estudadas em relação ao oceano.

\begin{tabular}{|c|c|c|c|c|}
\hline & & PC1 & PC2 & PC3 \\
\hline Variância explicada (\%) & & 40,3 & 17,1 & 11,7 \\
\hline Autovalores & & 4,43 & 1,88 & 1,29 \\
\hline Serra da Prata & & & 0,95 & \\
\hline Serra da Baitaca 2 & & 0,84 & 0,17 & 0,14 \\
\hline Serra da Baitaca 1 & & 0,79 & 0,26 & 0,24 \\
\hline Morro do Vigia & & 0,76 & 0,23 & $-0,12$ \\
\hline Morro do Salto & & 0,57 & & 0,48 \\
\hline Serra do Marumbi & & 0,55 & 0,43 & \\
\hline Morro Mãe Catira & & 0,41 & 0,22 & 0,69 \\
\hline Serra do Ibitiraquire & & 0,27 & 0,83 & 0,24 \\
\hline Serra Gigante & & 0,26 & & $-0,79$ \\
\hline Serra da Igreja & & 0,25 & 0,78 & \\
\hline Serra do Araçatuba & & 0,21 & & 0,76 \\
\hline Altitude & Rs & $0,70^{*}$ & 0,55 & 0,63 * \\
\hline Dist. Oceano & Rs & 0,43 & $-0,31$ & 0,28 \\
\hline
\end{tabular}

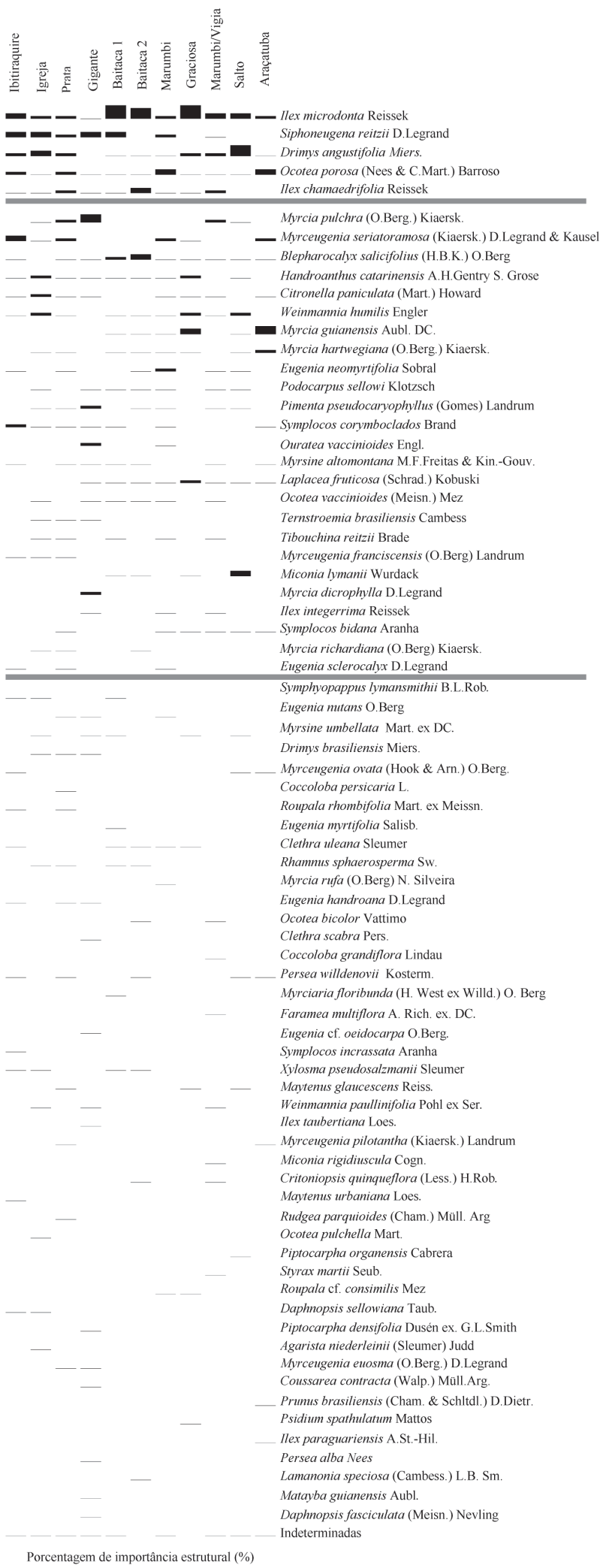

Figura 6. Espécies em ordem decrescente de porcentagem de importância estrutural nas florestas altomontanas amostradas em 11 levantamentos fitossociológicos de nove subserras do Paraná 


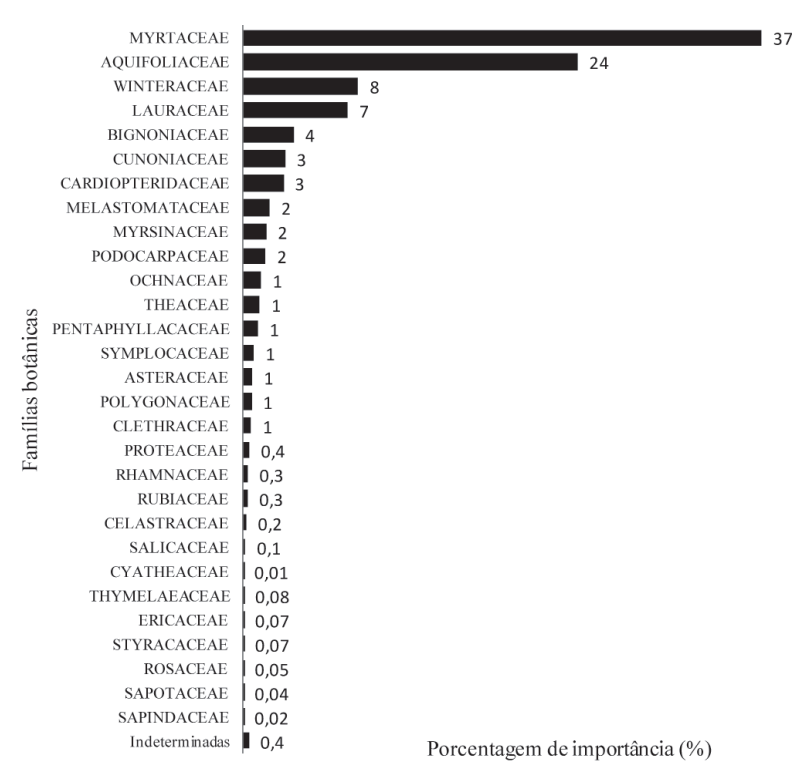

Figura 7. Famílias em ordem decrescente de porcentagem de importância estrutural nas florestas altomontanas amostradas em 11 levantamentos fitossociológicos de nove subserras do Paraná

Porcentagem de import ância

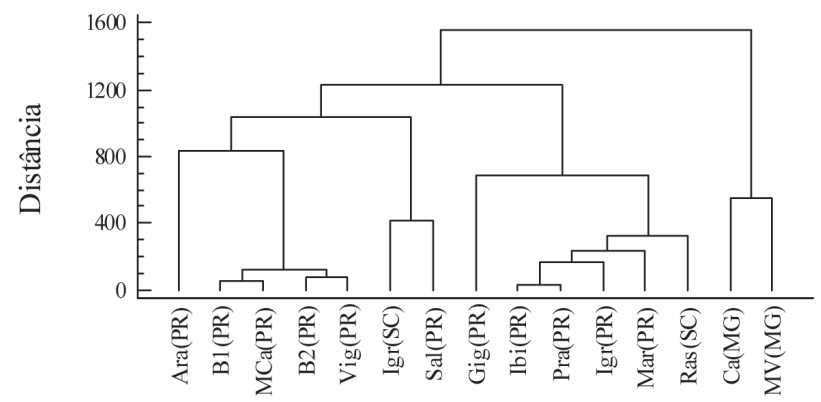

Figura 8. Dendrograma com base nos valores de importância estruturais das espécies amostradas em diferentes florestas altomontanas nas regiões Sul e Sudeste do Brasil. B1 - Baitaca 1 (Anhangava); MCa - Mãe Catira (Serra da Graciosa); B2 - Baitaca 2 (Anhangava); Vig - Vigia (Serra do Marumbi); Ara - Araçatuba; Igr(SC) - Morro da Igreja; Sal - Salto; Gig - Gigante; Ibi - Ibitiraquire; Pra - Prata; Igr(PR) - Serra da Igreja; Mar - Marumbi; Ras - Serra do Rio do Rastro; Ca - Camanducaia; MV - Monte Verde.

\section{Discussão}

Os levantamentos fitossociológicos realizados nas quatro subserras do presente estudo evidenciaram áreas basais, densidades, índices de diversidade de Shannon $\left(\mathrm{H}^{\prime}\right)$ e de Equabilidade de Pielou (J') similares aos publicados nos demais trabalhos realizados em outras serras do Paraná (Tab. 6). Os valores de riqueza um pouco maiores podem ser atribuídos principalmente à maior intensidade amostral, quando comparada aos demais estudos, o que possibilitou, mesmo com parcelas somente em formações típicas altomontanas, a inclusão de diferentes ambientes em relação à exposição, formas e declividades de rampa, solos etc.

Os trechos amostrados na Serra do Ibitiraquire apresentaram um menor $\mathrm{H}^{\prime}$ em relação às demais serras, à maior oligodominância, característica comum em habitats sujeitos à condições extremas (Scarano 2002). Nesta serra as cinco espécies mais importantes perfizeram $64 \%$ do PI, enquanto que para a Serra da Prata, com maior H', o valor foi de $46 \%$. Tal fato pode ser visualizado na Fig. 4, onde se observam as dez primeiras barras de cada Serra. Isto pode ser explicado pelas condições ambientais mais pronunciadas (menores temperaturas, incluindo congelamento e geadas mais severas, menor produtividade primária, decomposição mais lenta da matéria orgânica no solo, maior exposição aos ventos, etc.) à medida que se eleva a altitude e se distancia dos limites altitudinais montanos (Safford 1999).

A fraca relação entre o número de espécies por parcela e altitude dentro dos limites altomontanos, sugere uma leve tendência de florestas de maior altitude apresentarem um menor número de espécies por unidade de área dominando sua estrutura. Estudos envolvendo gradientes altitudinais (numa mesma montanha ou Serra) têm comprovado uma substituição e diminuição da riqueza de espécies por unidade de área com o aumento da altitude (Proctor et al. 1988, Roderjan 1994, Meireles et al. 2008). No presente trabalho, essa relação foi um pouco mais evidente utilizando-se o gradiente altitudinal dentro de uma mesma serra (Serra do Ibitiraquire). Entretanto, estes resultados indicam que a amplitude analisada talvez não tenha sido suficiente para capturar toda a variação necessária para o teste apontar relações mais significativas, ou, outras variáveis, principalmente geomorfológicas podem exercer maior influência.

Considerando dados da florística arbórea e não o número de espécies por unidade de área (Scheer \& Mocochinski 2009), a Serra do Ibitiraquire, a qual apresenta maiores altitudes entre as serras estudadas, passa a ter um maior número de espécies em sua formação altomontana (66 espécies), seguida da Serra Gigante (60 espécies), da Igreja (56 espécies) e da Prata (49 espécies). Os maiores gradientes altitudinais da Serra do Ibitiraquire, são fatores de grande influência na heterogeneidade ambiental (feições geomórficas e solos resultantes) e consequentemente, na maior riqueza de espécies arbóreas no patamar altomontano. Conforme comentado anteriormente, isto não ocorre em amostragens por unidade de área necessárias para a estrutura fitossociológica, como as do presente estudo.

S. reitzii está entre as três espécies mais importantes nas quatro serras amostradas, perfazendo o maior PI, considerando essas serras juntas (Fig. 4). Esse resultado difere dos sete levantamentos compilados por Koehler et al. (2002), em que essa espécie ficou em sétimo lugar em PI. Drimys angustifolia (provavelmente a maior parte tratada como Drimys brasiliensis nos demais levantamentos, anteriores a este) e I. microdonta ficaram com a segunda e terceira maiores porcentagens de importância entre as quatro serras do presente trabalho, concordando com a compilação de Koehler et al. (2002), porém ficando em segundo e primeiro lugar, respectivamente. Muitas espécies consideradas típicas por estes autores, tais como B. salicifolius e Laplacea fruti- 
cosa, foram consideradas comuns e ocasionais no presente estudo (vigésima quinta e quinquagésima quinta posições de PI), assim como M. seriatoramosa e C. paniculata, consideradas ocasionais por Koehler et al. (2002), ficaram na quinta e sexta posições nas quatro serras do presente trabalho. Conforme já comentado, apesar de serem formações altomontanas de uma mesma região fitogeográfica, tais diferenças indicam uma heterogeneidade ambiental entre os 11 trechos amostrados. Apesar da alta similaridade de espécies, grande parte delas ocupam diferentes posições de importância em cada comunidade.

Os grupos formados pelo dendrograma (Fig. 5) indicam uma influência da altitude agrupando as serras mais altas, no caso a do Ibitiraquire (média de $1700 \mathrm{~m}$ s.n.m.) com a da Prata (1400), e essas com a Serra da Igreja (1300), deixando a Serra Gigante (1000) isolada. As Serras do Ibitiraquire e da Prata ficaram melhor agrupadas, por apresentarem, por exemplo, nove espécies em comum entre as dez classificadas pelo maior porcentagem de importância (Fig. 5, Tabs. $1 \mathrm{e} 2$ ). As áreas amostradas na Serra da Igreja ficaram próximas do primeiro grupo por apresentar entre suas 10 espécies mais importantes, sete espécies em comum às dez mais impor- tantes desse grupo (Fig. 5, Tab. 3). A Serra Gigante ficou separada por apresentar somente duas espécies comuns entre as demais dez mais importantes nas serras (Fig. 5, Tab. 4). Como essa serra apresenta menores altitudes e menor gradiente altitudinal dentro de seu patamar altomontano, deve haver maior influência de espécies típicas ou transicionais do patamar montano, diferenciando-a das demais áreas amostradas.

Em todas as serras a família Myrtaceae apresentou o maior número de espécies, de nove na Serra do Ibitiraquire até 17 na Serra da Prata, de 33,6\% da densidade arbórea na Serra da Igreja, até 50\% na Serra da Prata, de 30\% da porcentagem de importância na Serra da Igreja, até 53,5\% na Serra Gigante. Aquifoliaceae foi a segunda família mais importante. Tais resultados concordam com os demais trabalhos em florestas altomontanas (Koehler et al. 2002).

É indiscutível a mudança estrutural, especialmente o porte dos indivíduos arbóreos, ao longo de um gradiente altitudinal. A floresta altomontana amostrada neste estudo na Serra da Prata (em média a 1400 m s.n.m.), considerando $\mathrm{DAP} \geq 10 \mathrm{~cm}$ (ou PAP $\geq 31,4 \mathrm{~cm}$ ), resultou em valores de DAP médio de 14,3 cm, valor inferior aos encontrados por Blum

Tabela 6. Parâmetros da estrutura e diversidade arbórea de diferentes florestas nebulares (montanas e altomontanas) nas regiões Sul e Sudeste do Brasil. Números em parênteses referem-se aos parâmetros do presente estudo calculados com PAP $\geq 15,7 \mathrm{~cm}$ para comparação com trabalhos realizados fora da Serra do Mar"

\begin{tabular}{|c|c|c|c|c|c|c|c|c|c|c|}
\hline Complexo & Local & $\begin{array}{c}\text { Região } \\
\text { fitogeográfica }\end{array}$ & Formação & $\begin{array}{l}\text { Altitude } \\
\qquad(\mathrm{m})\end{array}$ & $\begin{array}{l}\text { No de } \\
\text { spp. }\end{array}$ & $\begin{array}{l}\text { Densidade } \\
\text { (ind/ha) }\end{array}$ & $\begin{array}{c}\text { Área } \\
\text { basal } \\
\left(\mathrm{m}^{2} / \mathrm{ha}\right)\end{array}$ & $\begin{array}{c}\mathrm{H}^{\prime} \\
\text { nats/ind }{ }^{-1}\end{array}$ & J' & Referência \\
\hline \multirow{4}{*}{ 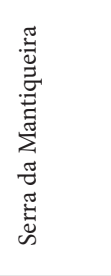 } & Carrancas, MG & Semidecidual & $\begin{array}{l}\text { montana / } \\
\text { altomontana }\end{array}$ & $\begin{array}{l}1440- \\
1513\end{array}$ & 217 & 2565 & 40,9 & 3,92 & 0,80 & $\begin{array}{l}\text { Oliveira-Filho et al. } \\
\qquad(2004)\end{array}$ \\
\hline & $\begin{array}{l}\text { Bocaina de } \\
\text { Minas, MG }\end{array}$ & Mista/Densa & $\begin{array}{c}\text { montana / } \\
\text { altomontana }\end{array}$ & $\begin{array}{l}1210- \\
1360\end{array}$ & 221 & 2574 & 34,6 & 4,15 & 0,82 & Carvalho et al. (2005) \\
\hline & Camanducaia, MG & Densa/Mista & altomontana & 1900 & 58 & 2001 & 48,1 & 2,9 & 0,71 & $\begin{array}{c}\text { França \& Stehmann } \\
\qquad(2004)\end{array}$ \\
\hline & Monte Verde, MG & Densa & altomontana & $\begin{array}{l}1820- \\
1940\end{array}$ & 64 & 3403 & 37,7 & 3,25 & 0,78 & Meireles et al. (2008) \\
\hline \multirow{2}{*}{ 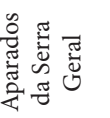 } & $\begin{array}{l}\text { Serra do Rio do } \\
\text { Rastro, SC }\end{array}$ & Mista & altomontana & $1400^{*}$ & 16 & 2824 & 52,6 & 1,58 & 0,57 & Falkenberg (2003) \\
\hline & Morro da Igreja, SC & Mista & altomontana & $1820^{*}$ & 13 & 3180 & 76,0 & 0,94 & 0,36 & Falkenberg (2003) \\
\hline \multirow{11}{*}{ 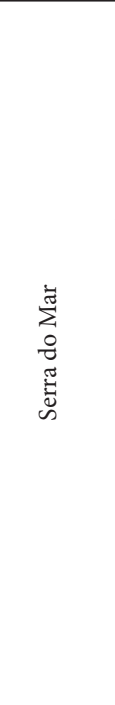 } & $\begin{array}{c}\text { Serra da Baitaca } \\
1, P R\end{array}$ & Densa & altomontana & $\begin{array}{c}1300- \\
1400\end{array}$ & 25 & 4419 & 29,3 & 2,22 & 0,65 & Roderjan (1994) \\
\hline & $\begin{array}{c}\text { Serra da Baitaca } \\
2, P R\end{array}$ & Densa & altomontana & $\begin{array}{l}1250- \\
1350\end{array}$ & 24 & 4830 & 41,8 & 2,28 & 0,71 & Portes et al. (2001) \\
\hline & Serra do Marumbi, PR & Densa & altomontana & 1400 & 29 & 4013 & 35,2 & 2,91 & 0,86 & Rocha (1999) \\
\hline & Serra do Marumbi, PR & Densa & altomontana & 1250 & 28 & 3140 & 29,5 & 2,88 & 0,86 & Koehler et al. (2002) \\
\hline & $\begin{array}{c}\text { Serra do Araçatuba, } \\
\text { PR }\end{array}$ & Densa & altomontana & 1400 & 17 & 2540 & 34,7 & 2,39 & 0,83 & Koehler et al. (2002) \\
\hline & Serra do Salto, PR & Densa & altomontana & 1390 & 20 & 4480 & 27,6 & 2,19 & 0,72 & Koehler et al. (2002) \\
\hline & $\begin{array}{c}\text { Serra da } \\
\text { Graciosa, PR }\end{array}$ & Densa & altomontana & 1350 & 19 & 4320 & 28,1 & 2,15 & 0,73 & Koehler et al. (2002) \\
\hline & $\begin{array}{c}\text { Serra do } \\
\text { Ibitiraquire, } \mathrm{PR}\end{array}$ & Densa & altomontana & $\begin{array}{l}1500- \\
1780\end{array}$ & $\begin{array}{c}26 \\
(24)\end{array}$ & $\begin{array}{c}4600 \\
(3333)\end{array}$ & $\begin{array}{c}40,3 \\
(37,9)\end{array}$ & $\begin{array}{c}2,50 \\
(2,35)\end{array}$ & $\begin{array}{c}0,77 \\
(0,74)\end{array}$ & Presente trabalho \\
\hline & Serra da Igreja, PR & Densa & altomontana & 1310 & $\begin{array}{c}34 \\
(33)\end{array}$ & $\begin{array}{c}4696 \\
(2912)\end{array}$ & $\begin{array}{c}30,5 \\
(27,6)\end{array}$ & $\begin{array}{c}2,62 \\
(2,58)\end{array}$ & $\begin{array}{c}0,74 \\
(0,74)\end{array}$ & Presente trabalho \\
\hline & Serra da Prata, PR & Densa & altomontana & 1400 & $\begin{array}{c}37 \\
(32)\end{array}$ & $\begin{array}{c}3533 \\
(2417)\end{array}$ & $\begin{array}{c}29,4 \\
(27,5)\end{array}$ & $\begin{array}{c}2,96 \\
(2,89)\end{array}$ & $\begin{array}{c}0,82 \\
(0,83)\end{array}$ & Presente trabalho \\
\hline & Serra Gigante, PR & Densa & altomontana & 1000 & $\begin{array}{c}41 \\
(31)\end{array}$ & $\begin{array}{c}6288 \\
(3648)\end{array}$ & $\begin{array}{c}29,6 \\
(25,8)\end{array}$ & $\begin{array}{c}2,63 \\
(2,41)\end{array}$ & $\begin{array}{c}0,71 \\
(0,71)\end{array}$ & Presente trabalho \\
\hline
\end{tabular}


(2006) em altitudes mais baixas na mesma montanha. Blum encontrou DAP médio de $20 \mathrm{~cm}$ a $1000 \mathrm{~m}$ s.n.m. no patamar montano e de $26 \mathrm{~cm}$ a $500 \mathrm{~m}$ s.n.m. no patamar submontano.

As alturas também são bastantes reduzidas nos patamares altomontanos, raramente com árvores alcançando $8 \mathrm{~m}$ de altura. A maior frequência dos indivíduos amostrados entre 4 e $5 \mathrm{~m}$ de altura é característica das florestas altomontanas típicas paranaenses (Roderjan 1994, Koehler et al. 2002). Esses valores são próximos aos observados nos trechos amostrados nos Aparados da Serra Geral, sendo alturas médias de 6,3 m na Serra do Rio do Rastro e de 7,3 m no Morro da Igreja (Falkenberg 2003) e também aos na Serra da Mantiqueira, entre 5,3 e 7,1 m de altura (Meireles et al. 2008).

$\mathrm{Na}$ menor cota altitudinal (1820 m s.n.m.) de floresta altomontana estudada por Meireles et al. (2008), foram observados dois estratos verticais, enquanto que na mais elevada (1940 m s.n.m.) foi observado apenas um estrato vertical. A configuração de árvores baixas em apenas um estrato vertical deve-se a respostas dos indivíduos aos rigorismos ambientais, sobretudo à incidência de ventos fortes e à limitação no espaço disponível para a sustentação radicial (Koehler et al. 2002). Isto sugere que os trechos amostrados na Serra da Mantiqueira por França \& Stehmann (2004), apesar de apresentarem altitude em torno dos $1900 \mathrm{~m}$ s.n.m., apresentam características de florestas montanas, com alturas de até $22 \mathrm{~m}$, compreendendo três estratos verticais, com alturas médias de 17,11 e $5 \mathrm{~m}$, respectivamente. No entanto esses valores se enquadram na descrição de florestas altomontanas realizada por Veloso et al. (1991).

Em relação à compilação dos dados de Koehler et al. (2002), a nova ordenação do presente trabalho abrangendo os 11 levantamentos nas florestas altomontanas na Serra do Mar no Paraná exclui B. salicifolius e $L$. fruticosa do grupo das cinco mais importantes e inclui $S$. reitzii e I. chamaedrifolia nesse grupo, classificado nesse trabalho como o das espécies típicas da formação, as quais perfazem até $50 \%$ da porcentagem de importância (Fig. 6). Sugere-se considerar do sexto ao trigésimo táxon (Fig. 6), como pertencentes ao grupo de espécies comuns, por juntamente com as espécies típicas perfazerem $90 \%$ do PI. Os 79 demais táxons podem ser classificados como ocasionais.

Myrtaceae (PI de 37\%) e Aquifolicaceae (24\%) predominam na estrutura arbórea da floresta altomontana no Paraná (Fig. 7). Os gêneros mais ricos em espécies arbóreas são Eugenia, com oito espécies, Myrceugenia e Myrcia, com seis espécies eIlex, Ocotea, Symplocos, com cinco espécies cada. Falkenberg (2003) também aponta a grande riqueza de espécies de Myrceugenia, em que juntamente com Siphoneugena ocupam mais da metade da abundância e dominância de "matinhas nebulares" dos Aparados da Serra Geral, em Santa Catarina. $\mathrm{Na}$ Serra da Mantiqueira, França \& Stehmann (2004) e Meireles et al. (2008) também destacam a importância de Myrtaceae, Lauraceae, Winteraceae e Aquifoliaceae, bem como os gêneros Myrceugenia, Drimys, Pimenta e Roupala.
O resumo dos parâmetros fitossociológicos de 17 levantamentos fitossociológicos apresentado na Tab. 6 demonstra que, considerando o critério de inclusão de ( $\mathrm{PAP} \geq 15,7$ $\mathrm{cm}$ ) dos demais trabalhos, as serras paranaenses indicaram menores alturas, DAPs e áreas basais, porém densidades similares. No presente estudo não foram consideradas árvores mortas que segundo França e Stehmann (2004), Meireles et al. (2008), entre outros, têm grande importância na estrutura das florestas altomontanas. Os trechos amostrados na Serra do Mar apresentaram menor riqueza e diversidade de espécies que os trechos na Serra da Mantiqueira e maior que os dos Aparados da Serra Geral.

Conforme dendrograma apresentado pela Fig. 8, apesar dos trechos amostrados nos Aparados da Serra Geral serem mais semelhantes floristicamente aos sítios da Serra da Mantiqueira (Scheer \& Mocochinski 2009), estruturalmente são mais similares aos da Serra do Mar paranaense. Isso é observado no primeiro grupo da Fig. 8, onde a Serra do Rio do Rastro (SC) se une ao subgrupo da Serra do Marumbi, que apesar de apresentar poucas espécies comuns às serras paranaenses, essas também apresentam altos valores de importância, tais como I. microdonta, S. reitzii e D. angustifolia. Ainda dentro desse grande grupo, a Serra da Igreja (SC) está agrupada com a Serra do Salto (PR), por apresentar D. angustifolia e Weinmannia humilis como espécies comuns e importantes estruturalmente, além de Myrceugenia ovata ( $=$ M. regnelliana var. gracilis).

Apesar de apresentarem espécies em comum às florestas altomontanas amostradas na Serra do Mar no Paraná (em torno de 15), tais como Pimenta pseudocaryophyllus, D. brasiliensis, Roupala rhombifolia, C. paniculata, M. umbellata, L. fruticosa, entre outras, as florestas altomontanas amostradas na Serra da Mantiqueira (França \& Stehmann 2004 e Meireles et al. 2008), apresentam valores de importância dessas espécies muito diferentes, os quais deixaram essas serras destacadas num segundo grupo (Fig. 8).

O primeiro componente principal, assim como o agrupamento por PI (Fig. 8), engloba serras próximas, com altitudes similares, como os sítios da Serra da Baitaca (1 e 2) e o do Morro do Vigia. O segundo componente principal, também agrupa as mesmas serras da análise de agrupamento. Tais serras apresentam muitas espécies em comum entre as mais abundantes e importantes em sua estrutura fitossociológica.

As diferenças entre espécies domininando a estrutura das florestas altomontanas estudadas na Serra do Mar, Aparados da Serra Geral e Serra da Mantiqueira, possivelmente, estão relacionadas ao grau de perturbação antrópica entre as serras amostradas, à influência da distância geográfica, dos diferentes centros de endemismo, do entorno tropical ou subtropical dominante (formação fitogeográfica), da geomorfologia, entre outros fatores. Os trechos altomontanos amostrados na Serra do Mar pertencem à Floresta Ombrófila Densa, enquanto que os amostrados nos Aparados da Serra Geral têm grande influência de elementos da Floresta Ombrófila Mista (áreas ecotonais), e 
alguns trechos da Serra da Mantiqueira (Oliveira-Filho et al. 2004) além das florestas ombrófilas, possuem influência de elementos das florestas estacionais.

\section{Agradecimentos}

Agradecemos à Fundação Grupo Boticário de Proteção à Natureza pelo patrocínio do "Projeto Altomontana - A Floresta Ombrófila Densa Altomontana e os Refúgios Vegetacionais Altomontanos no Paraná" e à Sociedade Fritz Muller de Ciências Naturais pelo apoio ao projeto. Agradecemos também às contribuições de Ruddy Proença, Samuel Arruda, Sandro M. Silva, Gustavo Gatti, Gilberto Tiepolo, Osmar S. Ribas, Gert G. Hatschbach, Juarez Cordeiro, Edimilson Costa, Marcos Sobral, Franklin Galvão, Renato Goldenberg, Alexandre Uhlmann, Luiz Carlos Pessenda, Gustavo Curcio, Paulo Labiak, Armando C. Cervi, Élide dos Santos, Olavo A. Guimarães, Marília Borgo, Miriam Kaehler, Marcelo Brotto, Fabrício Meyer, Carina Kozera, Rodrigo A. Kersten, Kelly Gutseit e dos revisores anônimos da revista.

\section{Referências Bibliográficas}

Angiosperm Phylogeny Group - APG III. 2009. An update of the Angiosperm Phylogeny Group classification for the orders and families of flowering plants: APG III. Botanical Journal of the Linnean Society 161: $105-21$.

Beard; J.S. 1944. Climax vegetation in Tropical America. Ecology 25: 127-158.

Beard, J.S. 1955. The classification of tropical American vegetation types. Ecology 36: 89-100.

Becker, A; Körner, C.; Brun, J.; Guisan, A. \& Tappeiner, U. 2006. Ecologi$\mathrm{cal}$ and land use studies along elevational gradients. 2007. Mountain Research and Development 27(1): 58-65.

Blum, C.T. 2006. A Floresta Ombrófila Densa na Serra da Prata, Parque Nacional Saint-Hilaire/Lange, PR - caracterização florística, fitossociológica e ambiental de um gradiente altitudinal. Dissertação de Mestrado, Universidade Federal do Paraná, Curitiba.

Bolstad, P.V. \& Vose, J.M. 2005. Forest and pasture carbon pools and soil respiration in the southern Appalachian Mountains. Forest Science 51: 372-383.

Bruijnzeel, L.A. \& Proctor, J. 1995. Hydrology and biogeochemistry of tropical montane cloud forests: what do we really know? Pp. 38-78. In: Hamilton, L.S.; Juvik, J.O. \& Scatena, F.N. (Eds.) Tropical montane cloud forests. New York, Springer Verlag.

Bruijnzeel, L.A. 2000. Hydrology of tropical montane cloud forests: a reassessment. Pp. 353-383. In: Proceedings of the Second International Colloquium (J.S. Gladwell, ed.). Paris, UNESCO.

Bruijnzeel, L.A. \& Hamilton, L.S. 2000. Decision Time for Cloud Forests. IHP Humid Tropics Programme Series n. 13, IHP-UNESCO, Paris, IUCN-NL, Amsterdan and WWF International, Gland.

Carvalho, D.A.; Oliveira-Filho, A.T.; Van Den Berg, E.; Fontes, M.A.L.; Vilela, E.A.; Marques, J.J.G.S.M \& Carvalho, W.A.C. 2005. Variações florísticas e estruturais do componente arbóreo de uma floresta ombrófila alto-montana às margens do rio Grande, Bocaina de Minas, MG, Brasil. Acta Botanica Brasilica 19(1): 91-109.

Doumenge, C.; Gilmour, D.; Perez, M.R. \& Blockhus, J. 1995. Tropical montane cloud forests: conservation status and management issues. Pp. 24-37. In: Hamilton, L.S.; Juvik, J.O. \& Scatena, F.N. (Eds.) Tropical montane cloud forests. New York, Springer Verlag.
Falkenberg, D.B. \& Voltolini, J.C. 1995. The montane cloud forest in southern Brazil. Pp. 138-149. In: Hamilton, L.S.; Juvik, J.O. \& Scatena, F.N. (Eds.) Tropical montane cloud forests. New York, Springer Verlag.

Falkenberg, D.B. 2003. Matinhas nebulares e vegetação rupícola dos Aparados da Serra Geral (SC/RS), sul do Brasil. Tese de Doutorado, Universidade de Campinas, Campinas.

França G.S. \& Stehmann, J.R. 2004. Composição florística e estrutura do componente arbóreo de uma floresta altimontana no município de Camanducaia, Minas Gerais, Brasil. Revista Brasileira de Botânica 27(1): 19-30.

Hamilton, L.S.; Juvik, J.O. \& Scatena, F.N. 1995. The Puerto Rico tropical cloud forest symposium: introduction and workshop synthesis. Pp.1-23. In: Hamilton, L.S.; Juvik, J.O. \& Scatena, F.N. (Eds.) Tropical montane cloud forests. New York, Springer Verlag.

Koehler, A.; Galvão, F. \& Longhi, S.J. 2002. Floresta Ombrófila Densa Altomontana: aspectos florísticos e estruturais de diferentes trechos da Serra do Mar. Ciência Florestal 12(2): 27-39.

Leigh Junior, E.G. 1975. Structure and climate in tropical rain forests. Annual Review of Ecology and Systematics 6: 67-86.

Maack, R. 2002. Geografia física do Estado do Paraná. Curitiba, Imprensa Oficial.

Magurran, A.E. 1988. Ecological diversity and its measurement. Princeton, Princeton University Press.

Martínez, M.L.; Pérez-Maqueo, O.; Vázquez, G.; Castillo-Campos, G.; García-Franco, J.; Mehltreter, K.; Equihua, M. \& Landgrave, R. 2009. Effects of land use change on biodiversity and ecosystem services in tropical montane cloud forests of Mexico. Forest Ecology and Management 258(9): 1856-1863.

Meireles, L.D.; Shepherd, G.J. \& Kinoshita, L.S. 2008. Variações na composição florística e na estrutura fitossociológica de uma floresta ombrófila densa alto-montana na Serra da Mantiqueira, Monte Verde, MG. Revista Brasileira de Botânica 31(4): 559-574.

Mocochinski, A.Y. \& Scheer, M.B. 2008. Campos de altitude na serra do mar paranaense: aspectos florísticos. Revista Floresta 38(4): 625-640.

Muller-Dombois, D. \& Ellenberg, H. 1974. Aims and methods of vegetation ecology. New York, John Wiley \& Sons.

Oliveira-Filho, A.T.; Carvalho, D.A.; Fontes, M.A.L.; Berg, E.V.D.; Curi, N. \& Carvalho, W.A.C. 2004. Variações estruturais do compartimento arbóreo de uma floresta semidecídua alto-montana na chapada dos Perdizes, Carrancas, MG. Revista Brasileira de Botânica 27(2): 291-309.

Portes, M.C.G.O.; Galvão, F. \& Koehler, A. 2001. Caracterização florística e estrutural de uma Floresta Ombrófila Densa Altomontana do morro Anhangava, Quatro Barras, PR. Revista Floresta 31 (1 e 2): 22-31.

Proctor, J.; Lee, Y.F.; Langley, A.M.; Munro, W.R.C. \& Nelson, T. 1988. Ecological studies on Gulung Silam, a small ultrabasic mountain in Sabah, Malaysia. I, Environment, forest structure and floristics. Journal of Ecology 76: 320-340.

Rocha, M.R.L. 1999. Caracterização fitossociológica e pedológica de uma Floresta Ombrófila Densa no parque estadual do Pico do Marumbi - Morretes, PR. Dissertação de Mestrado, Universidade Federal do Paraná, Curitiba.

Roderjan, C.V. 1994. A floresta ombrófila densa altomontana no morro Anhangava, Quatro Barras, PR: aspectos climáticos, pedológicos e fitossociológicos. Tese de Doutorado, Universidade Federal do Paraná, Curitiba.

Roderjan, C.V. \& Grodski, L. 1999. Acompanhamento meteorológico em um ambiente de Floresta Ombrófila Densa Altomontana no morro Anhangava, município de Quatro Barras - PR, no ano de 1993. Cadernos da Biodiversidade 2(1): 27-34.

Roderjan, C.V.; Galvão, F.; Kuniyoshi, Y.S. \& Hatschbach, G.G. 2002. As unidades fitogeográficas do estado do Paraná. Ciência \& Ambiente 24(1): 75-92.

Safford, H.D. 1999. Brazilian Páramos I. An introduction to the physical environment and vegetation of the campos of altitude. Journal of Biogeography 26: 693-712.

Scarano, F.R. 2002. Structure, function and floristic relationships of plant communities in stressful habitats marginal to the Atlantic Rainforest. Annals of Botany 90: 517-524. 
Scheer, M.B. 2010. Ambientes altomontanos no Paraná: florística vascular, estrutura arbórea, relações pedológicas e datações por ${ }^{14}$ C. Curitiba, Universidade Federal do Paraná. Tese de Doutorado, Universidade Federal do Paraná, Curitiba.

Scheer, M.B.; Gustavo, R.C \& Roderjan, C.V. 2011. Funcionalidades ambientais de solos altomontanos na Serra da Igreja, Paraná. Revista Brasileira de Ciência do Solo 35: 1113-1126.
Stadtmüller, T. 1987. Cloud Forests in the humid tropics: a bibliographic review. Tokyo and Turrialba. The United Nations University; Centro Agronomico Tropical de Investigacion y Ensenanza.

Veloso, H.P.; Rangel-Filho, A.L.R. \& Lima, J.C.A. 1991. Classificação da vegetação brasileira, adaptada a um sistema universal. Rio de Janeiro, IBGE.

Zar, J.H. 1996. Biostatistical analysis. 3 ed. New Jersey, Prentice Hall. 